Article

\title{
The Rhythm of Non-Places: Marooning the Embodied Self in Depthless Space
}

\section{Les Roberts}

Department of Communication and Media, School of the Arts, University of Liverpool, 19 Abercromby Square, Liverpool L69 4ZG, UK; E-Mail: les.roberts@liverpool.ac.uk

Academic Editor: Albrecht Classen

Received: 5 August 2015 / Accepted: 21 September 2015 / Published: 10 October 2015

\begin{abstract}
Taking as its starting point the spatiotemporal rhythms of landscapes of hyper-mobility and transit, this paper explores how the process of "marooning" the self in a radically placeless (and depthless) space - in this instance a motorway traffic island on the M53 in the northwest of England - can inform critical understandings and practices of "deep mapping". Conceived of as an autoethnographic experiment - a performative expression of "islandness" as an embodied spatial praxis - the research on which this paper draws revisits ideas set out in JG Ballard's 1974 novel Concrete Island, although, unlike Ballard's island Crusoe (and sans person Friday), the author's residency was restricted to one day and night. The fieldwork, which combines methods of "digital capture" (audio soundscapes, video, stills photography, and GPS tracking), takes the form of a rhythmanalytical mapping of territory that can unequivocally be defined as "negative space". Offering an oblique engagement with debates on "non-places" and spaces of mobility, the paper examines the capacity of non-places/negative spaces to play host to the conditions whereby affects of place and dwelling can be harnessed and performatively transacted. The embodied rhythmicity of non-places is thus interrogated from the vantage point of a constitutive negation of the negation of place. In this vein, the paper offers a reflexive examination of the spatial anthropology of negative space.
\end{abstract}

Keywords: non-places; liminality; rhythmanalysis; spatial anthropology; autoethnography; embodiment; mobility; motorways; northwest England 


\section{Marooned}

Marooned in an office block or on a traffic island, we can tyrannise ourselves, test our strengths and weaknesses, perhaps come to terms with aspects of our characters to which we have always closed our eyes ([1], p. viii).

Running across a northbound stretch of the M53 motorway one August afternoon in 2013, a backpack of basic supplies and equipment thumping against my spine, my progress was steered towards territory that could lay claim to few, if any, attributes of what might count as "place". Initially conceived of as a kind of autoethnographic experiment, the aim of this exercise was not to tyrannise myself, Ballardian style, as much as to try and "map" a sense of embodied dwelling (my "being there"): to examine how the "non-place" towards which I was headed might play host to a performative study of the rhythms and cadences of a radically liminal space. Hurtling headlong across the motorway, taking strategic advantage of a brief lull in the traffic flow, my goal was thus to maroon my self in a space defined in opposition to those routinely inhabited or imagined: a negative space against which the more mundane geographies of everyday mobility might be cast and measured.

The liminal space in question, like that which forms the setting of Ballard's story, is a motorway traffic island. A "concrete island", to borrow from the title of the 1974 novel, is a reasonably apt descriptor, but only inasmuch as this too is constitutive of a negative frame of reference: an island surrounded by a sea of concrete (and tarmac) rather than one that is made of concrete. Indeed, it was partly the lushness and density of the island flora that first drew my attention to this topographic anomaly when driving past it on my way to and from Liverpool. The island's anomalous status (of which more later) was another factor that piqued my initial curiosity, setting in motion the designs of a Crusoe-esque quest spurred as much by the question as to why such a feature existed at all as by that which probed the island's more experiential or "rhythmanalytical" $([2,3])$ dimensions. What might be gleaned, I had wondered, from time spent self-marooned on this motorway island; a day and night cocooned by nothing but the hiss and roar of high-speed traffic? What might a spatial anthropology of a such a radically deterritorialized landscape throw up that could not ascertained by other modes of enquiry? (What does the "being there" element bring to the table?) Given the depthless and socio-historically "empty" fabric of this non-place, to what extent might a project of "deep mapping" make sense of a space that, save perhaps the occasional visitation by motorway maintenance workers, has remained cut off from all human contact?

But then had it? This too formed part of what I had hoped to shed some light on. Might I find evidence of others having "made the crossing" and spent time on the island (for whatever purpose)? Might my being there serve in some way to draw out or tentatively sketch an anthropology of this territory? Or might I end up finding myself in search of a rationale for an excursion destined to elicit little that might be construed as anthropologically or geographically insightful, other than perhaps that which speaks to more generic concerns with, for example, "edgelands", "psychogeography", "liminality", "non/more-than-representational geography", or other such modish frames of reference? Posed more directly: Beyond the more broadly conceived goal of exploring the spatial anthropology of non-places - a reflexive enquiry into what could be described as the negation of the negation of place - what, exactly, is the point of marooning the embodied self in depthless space? 


\section{Tuning in, Timing Out}

To begin to flesh out a provisional response to this question, the idea of "tuning in" provides a useful and suggestive point of departure. Finding the right frequency is to connect or find resonance with a space of communication defined in terms of modulation and rhythm rather than infrastructural and material form. Viewed thus, for those marooned in "non-places" rather than in transit through them, adjusting - mindfully - to the temporal geographies of motorway space is akin to tuning the dial on a car radio. Rather than confronting the "white noise" of traffic that defines a dissonant or transitory moment of encounter (such as my precarious transit to and from the island), the bestowal of prolonged durational time - the lacuna ([4], p. 19) period spent in the midst of flow and movement - provides the motorway dweller with a space by which to ease the embodied self into a habituated sense of rhythmic order, as if slowly beginning to make out the shape and contour of a recognisable tune coming through the airwaves. In autoethnographic terms, as a key methodological objective, "tuning in" thus became an integral part of the wayfinding and habituation process by which I familiarized myself with and made sense of the environment I had made my temporary home. By extension, in cartographic terms, "reading the rhythm" of the space is perhaps the most instructive way of thinking about the project as an exercise in "mapping" ("deep" or otherwise) oriented around the central axis of the embodied and situated self.

In the absence of topographic detail, embodied immersion in the liminal spatialities of a motorway island is therefore as much an enquiry into the phenomenology of time as it is that of space or "non-place". More accurately, it is necessary to look upon the temporal geographies under investigation in terms of an experiential "time out" conceived of as a disruption of the temporal flow that otherwise structures a sense of everyday habitus and being-in-the-world [5]. As Edensor notes, "[t]he usually unreflexive sensual and rhythmic attunement to place and familiar space may be confounded when the body is 'out of place" ([3], p. 5). Accordingly, it is to what Morris has referred to as the "metaphorai of the pause" ([6], p. 41) that our rhythmanalytical attention is principally addressed. ${ }^{1}$ Concerned less with arrival and departure in terms of the consummatory passage through a space or non-place of transit, the experiential space-time of the island is more redolent of an embodied sense of stasis: a temporal unfolding of spatial restriction where movement is defined in relation to the immobility and longueur of the liminal "pause" ([9], pp. 82-83; [10], p. 5). Horizons are scaled down to the immediacy of the moment and the ebb and flow of time that is mobilized in vehicular form. From the axis point of the island Crusoe, cast ashore and stranded from a world in perpetual flux, the north- and southbound rhythms of the motorway inhibit any sense of resolution or consummation other than that by which the island-body is brought into being as a time unto itself.

In his study of memory and oblivion, the anthropologist Marc Augé ([11], pp. 55-84) sets out what he refers to as three "figures of oblivion" that structure the temporal dialectics of remembrance and

1 The word "metaphor" is derived from the ancient Greek for transfer, or transport. Moreover, in modern-day Greece, vehicles of mass transportation, such as the bus and the train, are called metaphorai ([7], p. 115). Viewed thus, the "metaphorai of the pause" can be understood as the movements that are metaphorically transacted at what are otherwise fixed (immobile) points where trajectories of arrival and departure intersect (such as, in Morris's [6] example, a motel—see Roberts [8]). 
forgetting. The second of these, suspense, refers to the cutting off of the present from the past and future. In ritual terms this approximates to the separation phase of Arnold van Gennep's tripartite "rite of passage", or Victor Turner's notion of "communitas" - an in-between state in which the oblivion of past returns and future beginnings (or of points in time and space already departed as well as those yet to be arrived at) shapes a temporary state of suspended presentness [12-14]. The motorway island, like that of the motorway more generally, is a liminal space of oblivion par excellence. Memory is afforded little in the way of traction. Anthropological place, in the Durkheimian sense of an organic social space that is "relational, historical and concerned with identity" ([15], p. 77), has limited application in the case of environments such as these. The mirror-like "surface sheen" (the functional prerequisite of a space given over to pure mobility) prevents the slow absorption of time and memory; it can only be "layered" or "embedded" insofar as the mode of transport itself becomes the site of topographic depth ([3], p. 6 ; [16-18]).

A brief caveat at this point would be to acknowledge that, yes, Augé's non-place thesis to the effect that "place" in supermodernity becomes emptied and rendered devoid of history, memory and organic social relations is not without its detractors. As Merriman, for example, has noted, to look upon airports or motorways as "non-places" runs the risk of overlooking "the complex habitations, practices of dwelling, embodied relations, material presences, placings and hybrid subjectivities associated with movement through such spaces" ([19], p. 154; [20]). Whilst such a risk might arguably relate more to the peddling of an absolutist conception of non-places (which Augé himself does not subscribe to, noting that place and non-place are like "opposed polarities: the first is never completely erased, the second never totally completed" ([15], p. 79)), this observation nevertheless draws much needed attention to the complex experiential and embodied dynamics of these spaces and holds in check the otherwise default setting that non-places are, almost by definition, intractably placeless.

Yet to the extent that we could ascribe a (rather clumsy) measure of "non-place-ness" in our analyses of specific spaces and topographies, there is clearly a distinction that could be drawn between, say, a motorway service station or airport terminal and the kind of space that forms the basis of the present study. Embracing the abstraction, solitude, and liminality of this deterritorialized landscape, my curiosity was driven in no small part by the degree to which the island is an exemplar of a radically placeless space, and by what, as a consequence, this might translate to in terms of a strategically enforced practice of embodied dwelling. "What is the time of such a non-place?" is a question that most succinctly draws together the various threads of what I conceived the project to be reaching for in terms of its autoethnographic remit.

\section{Time Out (of Place): Off-Road Journeys}

If motorways are an example of what Dimendberg ([21], pp. 177-78) refers to as "centrifugal space", where the density of the urban centre is radially dispersed throughout what are increasingly abstract, hyper-mobile and virtual spaces and networks, then the "walking cure" ([21], p. 109) prescribed by the flaneur or psychogeographer can be looked upon as a kind of counter force. This need not necessarily be centripetal in its orientation, but does at least serve to anchor affects of place and memory in spaces that are otherwise experienced as abstract or in some way drained of local colour and depth. The tactical interweaving of imaginative and embodied worlds with the concrete 
materiality of everyday urban form - "tramping asphalted earth in alert reverie", to borrow writer Iain Sinclair's suggestive phrase ([22], p. 4) — thus allows for the layering and accretion of anthropological place, if by this we mean places invested with humanistic attributes, the "impure content..."-_....lived time, everyday time, ...bodies with their opacity and solidity, their warmth, their life and their death" ([23], p. 97) — that processes of spatial rationalisation can prove so adept at flushing out.

By extension, the motorway flâneur - as illustrated by Sinclair's [24] epic trek around London's M25 orbital motorway-is someone whose cartographic proclivities are steered towards the deep mapping or "deep topography" [25] of landscapes through, across or above which, ordinarily, the subject is centrifugally slung. Morse notes that "[f]reeways are displaced in that they do not lie earthbound and contiguous to their surroundings so much as float above or below the horizon" ([26], p. 197). A topographic study premised on the notion of deep mapping is thus one that is bent on reversing or going against the grain of the motorway conceived of as a rational and functional space. A reworking of Morse's observations along these lines would instead stress that: motorways are emplaced inasmuch as they are made earthbound and contiguous to their surroundings by the embodied practices of a deep cartographer for whom horizons are experienced in the simultaneity of the here and now. Presentness - a dalliance with off-road space (the chronotope of the road traded for that of the route or way) - denotes earthiness in that time is re-routed and made consonant with the rhythms and textures of the ambulant body.

If "time out" represents a temporal disruption of the functional space-time linearity of the motorway, then "off-road" is its spatial correlate $(c f .[8,27])$. Off-road here can refer to the physical edgelands of motorways (such as, in my case, a motorway island situated between carriageways, or those outlying liminal landscapes that hug the orbital colossus of Sinclair's M25). It can also point to the flights of imagination and creative reverie that the mundane features of motorways can help foster [26,28,29]. A phenomenon that will be all too familiar to motorists who regularly drive on motorways is the experience of slipping into "autopilot" for a period of miles/minutes/hours and of subsequently "coming to" with little recollection or awareness of having been driving, almost as if s/he had temporarily been spirited away to another space entirely. In Morse's “An Ontology of Everyday Distraction", she examines the ways that "non spaces" such as freeways/motorways or shopping malls can promote a state of mind whereby the individual is "disengaged from the paramount orientation to reality" and experiences a "spacing out' or partial absence of mind" ([26], pp. 200, 194, emphasis in original). It is instructive to look upon these lapses and moments of "spacing out" not as ellipses (akin to film or television footage that has been "edited out") but rather as negatives through which we encounter the flux of thought and mental flânerie: imaginative worlds that project a different inflection on what we might understand by the concept of non-place/space. This is an idea that finds resonance with Osborne's view that non-places may potentially be configured "less as 'empty' or 'solitary' versions of traditional places and more as radically new ontological types of place, constituted qua places through their relations to another spatiality" ([30], p. 189, emphasis in original). It also brings to mind Marin's discussion of the "spatial play" of utopic practice: utopia (a conflation of the Greek words outopia and eutopia - "no place" and "good place") conceived of as the "reverse image of this world, its photographic negative" ([31], p. 242). The non-places of the motorway, in other words, refer 
to both the anthropologically inert or "empty" spatialities of the built environment and the "other spaces/places" of the imagination that the mundane roadscape [29] helps conjure into being.

In director Laurent Cantet's 2002 film L'Emploi du temps (the Anglophone title of which is Time Out) we are confronted with a protagonist for whom the motorway offers the possibility of escape from a psycho-social world he is increasingly anxious to forget (or "space out"). Vincent is a French middle-class executive who conceals from his family and friends the fact that he has been sacked from his consultancy job. Maintaining the illusion that he has secured a prestigious new position in Geneva working for the United Nations, he spends most of the week in his car driving through the French and Swiss countryside, telephoning his wife from car parks or motorway service stations, and pretending that he has just come out of business meetings. ${ }^{2}$ What is immediately striking about Time Out's cinematic geographies $[33,34]$ is the inert quality of the temporal and spatial landscapes that dominate Vincent's everyday world. Time is as dead and empty as the non-places he inhabits. In the absence of any recognisable social framework, "normality" is rehearsed at scheduled time slots (early morning, lunchtime and evening) and in allotted "social" arenas, such as motorway dining areas (and, later in the film, hotel lobbies and corporate reception areas). In these structured moments of contractual sociality Vincent's double life acquires its fullest expression, most notably in the phone conversations he has with his wife, but also in the momentary encounters with other transitory passengers, whose shared anonymity allow him to temporarily maintain the illusion of a social role and identity. In all other respects, movement "fills in the gaps" of distraction. The abstract spaces of the motorway become a welcome refuge from the responsibility and complexity of his situation. Indeed, as Vincent later confides, it was his increasing reluctance to leave his car that precipitated his eventual dismissal from his consultancy position. Driving hundreds of kilometres to attend pointless meetings was, he confesses, the only thing about the job he enjoyed: "Alone in the car...thinking about nothing...smoking and listening to music..."

Time Out offers an immersive illustration of the capacity of motorway non-places to effect a "spacing out" of some of the more mundane facets of everyday life and to render possible the creation of "other worlds": spaces of the imagination into which the self can take temporary flight. In Vincent's case the rhythms of the day are not dissimilar to those that define his normal social routine; the difference lies in the degree to which this normality may be held in abeyance and a creatively re-ordered reality substituted in its place. As a consequence, the constitutive liminality that governs the ritual and experiential potentiality of these spaces is harvested for its essentially transformative properties, however short-lived or psychologically precarious these may be. To these ends, it is apparent that another objective of my island sojourn has been to enquire into the changes potentially wrought by an intermeshing of the embodied self with the mobile rhythms of a radically negative space. Irrespective of disciplinary intentionality_-indeed, apart from a somewhat vague nod towards something loosely

2 The film draws much of its inspiration from the real-life case of the Frenchman, Jean-Claude Romand, who, like Vincent, was a Mr. Ripley character living a life of deception, pretending to his family and friends that he worked as a doctor and researcher at the World Health Organisation, while in reality spending his days driving aimlessly around the Alps. Romand somehow managed to sustain this for 18 years, his otherwise normal middle-class lifestyle financed by money embezzled from friends and relatives. When, in 1993, Romand's double life was finally exposed, he responded by murdering his wife, children and parents, and by attempting to take his own life [32]. 
referred to here as "deep mapping", how exactly might, or should a project such as this be labelled? — what it does point to is a praxis of the self as a fundamentally creative act: an embodied practice of what the geographer David Crouch [35] refers to as "spacing".

\section{Rhythm Mapping: An Exercise in Composition}

Perhaps inevitably, the Ballardian backdrop to a discussion that fixes its attention on a concrete traffic island leads us at some point to consider the phenomenological significance of boredom. Boredom does indeed come with the territory ${ }^{3}$. To briefly return for a moment to the M25, in Iain Sinclair and Chris Petit's 2002 experimental documentary London Orbital, boredom becomes a threshold that is there to be crossed; the M25, a "doorway into another reality". For Sinclair and Petit, the more that one is drawn in to the motorway's almost hallucinatory force field, the more it appears to exude its own consciousness. The goal of the motorway flâneur-whether artist, photographer, filmmaker, cartographer, anthropologist, psychogeographer, "motorway shaman" (or combination thereof) - is to in some way access this affective space (and in so doing help cultivate it). Deep mapping or deep topography comes to resemble a form of meditation practice:

[T]he M25 is negative space - an energy drain. To enter it is to enter dead time; clockwise or anti-clockwise. More than other motorways, the M25 is designed to test the thresholds of boredom. It eliminates any romantic notion of boredom, but for the addicted it has its attractions: it is mainline boredom, it is true boredom, the quest for transcendental boredom...

(narration by Chris Petit in London Orbital)

Whether transcendence can ever meaningfully be achieved is another matter. What motorway boredom inevitably leads to is perhaps an integral part of the journey itself, even if this is just the eventual exit up a slip road and a welcome retreat to a less transcendent geography of roundabouts, crossroads, and traffic lights ([15], p. 57; [38]). Towards the end of London Orbital we learn that one of the filmmakers' fellow travellers, the artist John Sargeant, fails in his own endeavour to transcend the limits of motorway boredom. Having retreated to a concrete island interchange to observe the road, his quest ends in inertia and disillusion: "After running too long on empty, everything stops-boredom, like rust, becomes entropy", remarks Petit, by way of rumination.

London Orbital is a film whose aesthetic and formal properties are well in keeping with its subject matter. The surveillant gaze of the moving image - the "flat literalness" of a digital journey through negative space-feels as hypnotic as the experience of driving (or being driven) through the abstract

3 Edensor cites the results of a report conducted into rail commuting, noting that only two percent of respondents found travelling boring. Edensor comments that "[T]he automaticity commonly ascribed as boring, allows commuters to dream, read, telephone and plan...” ([36], p. 198). This dialectical understanding of boredom points to the ways that boredom sets the experiential conditions for its alleviation through the activities it engenders. This is a similar approach to that which underpins the idea of non-places harbouring the seed or potentiality by which placelessness is negated and "place" (re)established through practice. Similarly, from a Lefebvrean perspective, the "felt experience of dullness, boredom and estrangement", as Rob Shields notes, is seen as an "[important] source of Utopian inspiration and revolutionary resolve" (in Fraser [37]). For discussion of the imbrication of the literary and the everyday in Lefebvre's work see Ben Fraser's Toward an Urban Cultural Studies ([37], pp. 95-120). 
spaces of the motorway itself. The film sears its unrelenting and driving rhythm on the mental landscapes of the "voyager-voyeur" ([39], p. 105) in such a way as to slip, momentarily, into the experiential flux of actual motorway driving (and vice versa - the cinematic experience conjuring an embodied memory of motorway driving spaces). It is for this reason that London Orbital has never felt far from my peripheral vision as I have set about conducting my own enquiries into negative space. The film is also very much the product of two interlocking but otherwise separate spatial methodologies: Petit's ruminant journeys around the motorway by car; and Sinclair's more peripatetic adventures on foot. If the abstract rhythms of the former have felt more closely in sync with my own experience of motorway driving (the journey up and down the M53 is part of my regular commute to and from work), the latter - a form of motorway navigation that deviates quite sharply from what might be regarded as routine - taps into rhythms that are closer to those encountered in my time spent on the motorway island.

There is, perhaps, an inclination to think of motorways as in some way neat, ordered, and "smoothly" configured to efficiently accommodate the unimpeded flow and circulation of traffic (even if this functional imperative routinely falls short of motorists' expectations). While motorways of course do exhibit these qualities it only takes the briefest of "off-road" diversions to access an altogether different landscape, one that is less ordered, more feral, and seemingly untroubled by the meshworks and desire lines of human activity. Similarly, when thinking about the kind of rhythms we might associate with motorways (from the mobile perspective of driver or passenger) it is those that map on to the experiential geography of the journey itself that are of significance: the transito ${ }^{4}$ rush of forward momentum; the frustration induced by traffic jams or of slow crawls along congested carriageways; the violent collision of metal on metal; the parallel tracking of musical rhythm from the car radio or CD player ([36], p. 198; [41]). What is less likely to draw comment is the slow, arduous, and often painful progress of the body as it hacks its way through a dense thicket of trees and undergrowth, a growing blanket of dusk prompting a briskness of pace.

Nature, left to itself, makes no concession to the human visitor. This is an entry from my field notes, written shortly after my arrival on the island. Very dense vegetation-difficult to move through island to the north, flatter area. Boredom had little purchase in this environment, at least in these early stages of my residency; there was simply no time to be bored. The practical demands of orientation and of finding a suitable location that might serve as base camp (a clearing flat and comfortable enough to accommodate a body in a sleeping bag) imbued the landscape not with inertia but character and form. This was no negative space; no anomalous feature on the map. In the first instance it is an island woodland. Screen out the traffic noise and the fact that it was surrounded at all sides by motorway and there is little to distinguish it from other wooded areas that are located "inland" off the motorway.

The "north, flatter area" towards which I was headed is, in fact, not north at all, but west of my initial location. The directional geometry of the motorway (northbound and southbound) had imprinted

4 Transito is a concept that Guiliana Bruno adapts from the Italian philosopher Mario Perniola. This theorizes the spatialization of desire as inscribed in physical and mental motion, incorporating states of transit, transition, movement and circulation. With its emphasis on flows, movements and the spatial enactment of desire transito addresses itself to transgressions of social, spatial and moral boundaries, and the desires and kinaesthetic pleasures of embodied perception (see [40], p. 222). 
itself on my cognitive map of the island in such a way as to streamline space and remove all but the most abstract of geographical forms. The non-place of the map had territorialized a space that in all other respects was anything but uniform or geometrically defined. This spatial confusion would become all the more apparent after I had spent a night on the island. The "north, flatter area" was where I would set up camp and initiate my nocturnal watch over the now moonlit and street lamp-bathed island (Figure 1). Come morning, when my exploratory adventures would begin proper, the sense of my being directionally-challenged soon became clear:

Major orientation problems...I thought I was heading northwards [west] on the exploration this morning, but was in fact heading south [east]. Confusion over which side of the motorway I am on. I thought I was on the opposite side from the point where I landed but I am in fact on the same side, facing towards Hooton and south, not northwards.

(Field note extract)

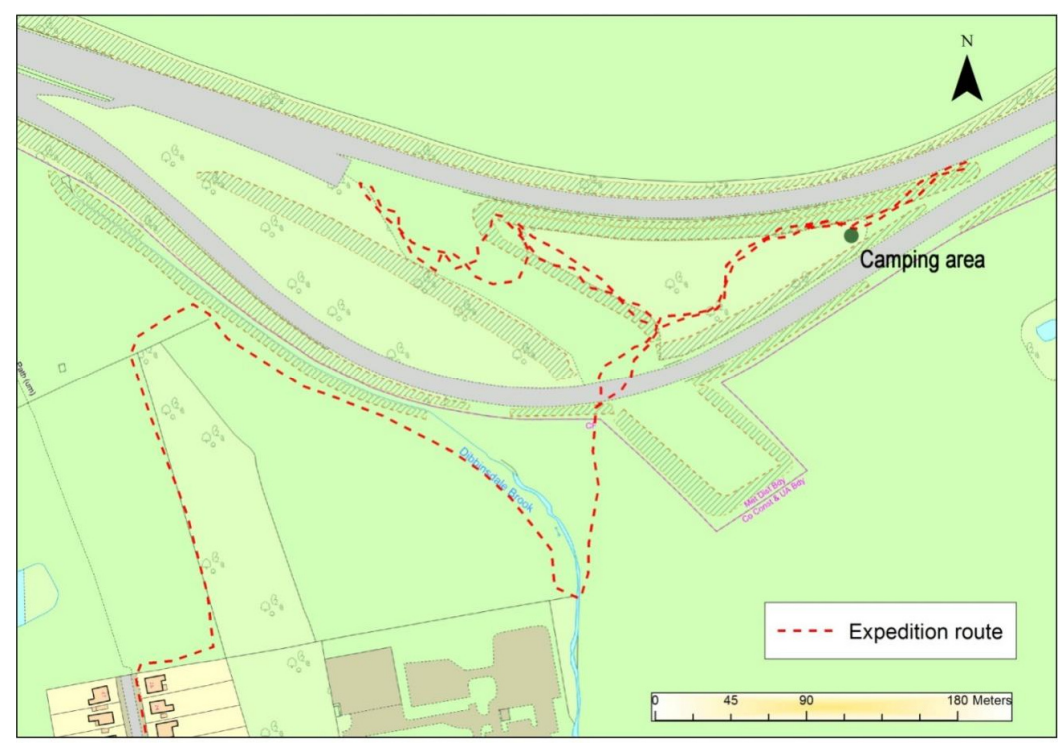

Figure 1. Ordnance Survey (OS) map of island showing expedition route, camping area and crossing points (1:2196). (Map data: (C) Crown Copyright and Database Right [2013]. Ordnance Survey (Digimap Licence) $).^{5}$

This field note entry was recorded more than two hours after I had reached what I thought had been the most northerly (westerly) tip of the island. Lack of sleep, coupled with a befuddled sense of space, had served to unstitch the territory from its geo-locational points of anchorage, transforming it into a residual product of my ever so slightly wired imagination.

Hubcaps, coke cans, an exhaust cylinder, half-brick, empty bag of garden chippings, large metal frame - possibly part of a sign, Quaver [crisps] packet, length of polystyrene coving,

\footnotetext{
5 All images and audio-visual data are copyright of the author unless otherwise stated. In addition to the embedded visual content, hyperlinked digital materials can be accessed in the form of audio sound files (see Figures 5 and 7 and [42-43]) and a video shot during the period of fieldwork on the island [44].
} 
take-away coffee cup with lid, traffic cones (x 2), seat of office chair, rusty metal rope (with noose).

(Field note extract)

The carpet detritus that littered the floor of the island - the sole vestiges of a proximate human presence (Figure 2) — contributed to the general sense of dislocation I was experiencing. The coming to rest of objects that had been washed up at random moments helped define an island ecology that has developed in isolation from the more manicured and "legible" landscapes of the motorway and surrounding area. In other words, despite the relentless soundscape of a chaotic and busy world "out there", the topographic texture of the island conspires towards an interiority of place and experiential dwelling. In an environment such as this the mind is left to follow its own course: consciousness and geography alike become unmoored. The sedentariness or restricted spatiality of the body provide fertile ground for the imagination to cut loose and take flight.

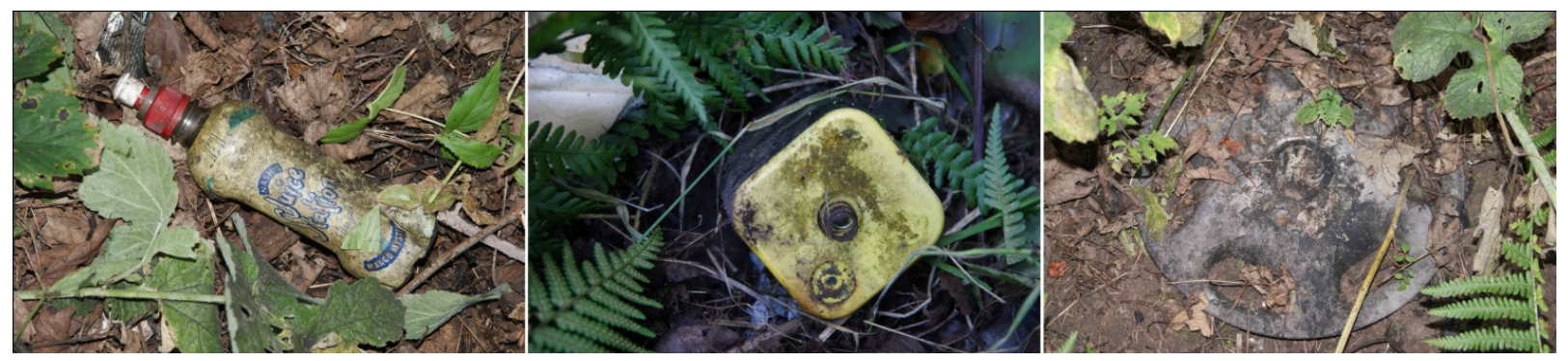

Figure 2. Hybrid textures.

I cannot recall now exactly at which point the significance of the soundscape began to leave its mark, but the challenges encountered in terms of spatial awareness were more than compensated by the cartographies of sound that became the default sensorial mechanism by which a habitual and "grounded" sense of space and place was provisionally secured. What might be understood as a "map" of the island non-place was thus one that derived its form from the pulses and sonic rhythms established by the unremitting flow of vehicular traffic. In retrospect, these island rhythms probably began to fully seep their way into the sensorium of my body in the early hours of the morning when I had bedded down to what would prove to be an extremely fitful sleep. The following field notes, written at 10:40 p.m. as I attempted to make myself comfortable for the night, provide some indication of the experiential space that had begun to take shape around me:

Lying on mattress, blow up pillow. Looking up at the canopy and stars beyond. Full moon to the east [north]. As cars go by light ripples through leaves of the canopy. Sound of cars, like waves - irregular rhythm. Unwavering, few variations (bar the odd motorbike or lorry). They seem to have a life/biorhythm of their own, as if they are part of a bigger entity. Feeling of isolation - each one a world unto itself, surrounding my own isolated space...I wonder if the relentless hiss/rush of cars will have an effect on my sleeping/dreaming state (if I manage to sleep...).

(Field note extract) 
At 4:17 a.m., I am awoken by the sound of a tin can, thrown from a car, rolling along the motorway. No doubt, in time, this too would become a constituent part of the island's alluvial terrain: hybrid flotsam that, like me, finds its place in the entropy of motorway edgelands.

In a space — or non-place — such as this, the night waves and rhythms can cast something of a spell (Figure 3). The traffic noise - the soundscape — seems louder and more prominent than during the day (lorries and heavy goods vehicles make a particularly thunderous impression). As a consequence, it becomes all the more enveloping; its peaks and lulls secrete an inexorable pattern that lodges itself in the penumbral zone between consciousness and slumber. Despite its heightened volume, the traffic may even have had something of a soporific effect, although this is less easy to recall with any degree of accuracy. Indeed, as in autoethnographic terms I had become, for three or four hours at least, an "unreliable narrator", it is the sound recordings I had been making since my arrival on the island that provide the sole means of documentation during the few hours of sleep.

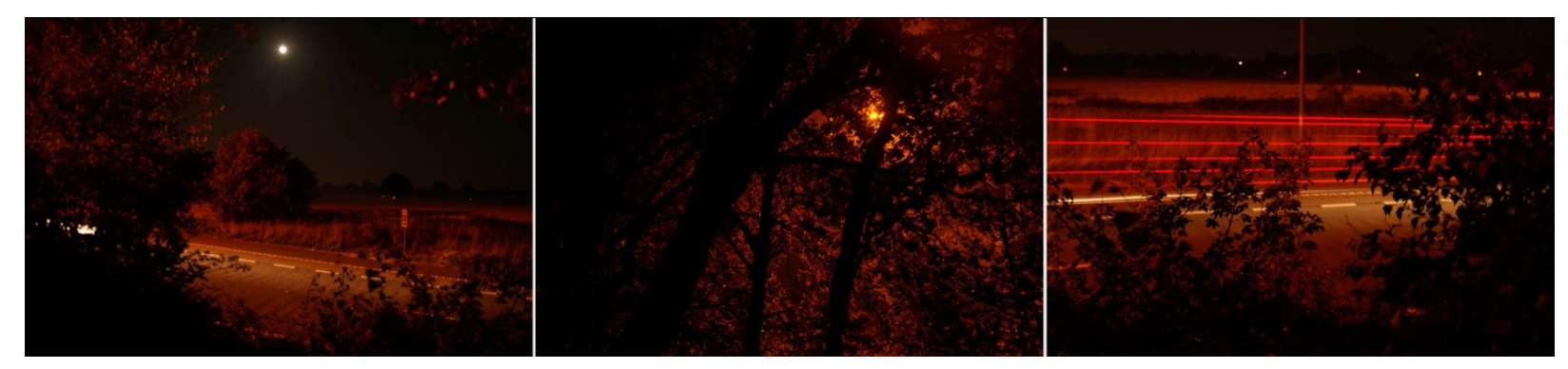

Figure 3. Night waves.

Insofar as the all-embracing soundscape so clearly defines the embodied spatialities of the island, it is the frequency, intensity and rhythmicity of the traffic noise that provide the raw material from which to best engineer a cartographic "capture" of this experiential space. The time domain images extracted from the sound recordings (see Figures 4-8), if processed in conjunction with the audio recordings themselves (see links to audio clips - Figures 5 and 7), render possible a form of locational positioning whereby, representationally at least, the island may be re-visited or re-inhabited and a rudimentary degree of orientation established. As maps, the sound capture images delineate the temporal geographies of the island in ways that give an impression of the rhythmic modulations that both anchor the space in the durational flux of phenomenological time and track the nocturnal and diurnal rhythms of a social ecology built on mobility and flow. This latter, more cyclical space-time transcends the time-stamped singularity of the captured moment (the contingent occurrence of my "being there") to form the entrenched social rhythms that are a constellated product of the myriad "spatial stories" [7] and everyday mobilities of the motorway wayfarer. Accordingly, as Lefebvre suggests, "[t]he cyclical is social organisation manifesting itself. The linear is the daily grind, the routine, therefore the perpetual, made up of chance and encounters" ([2], p. 30). 


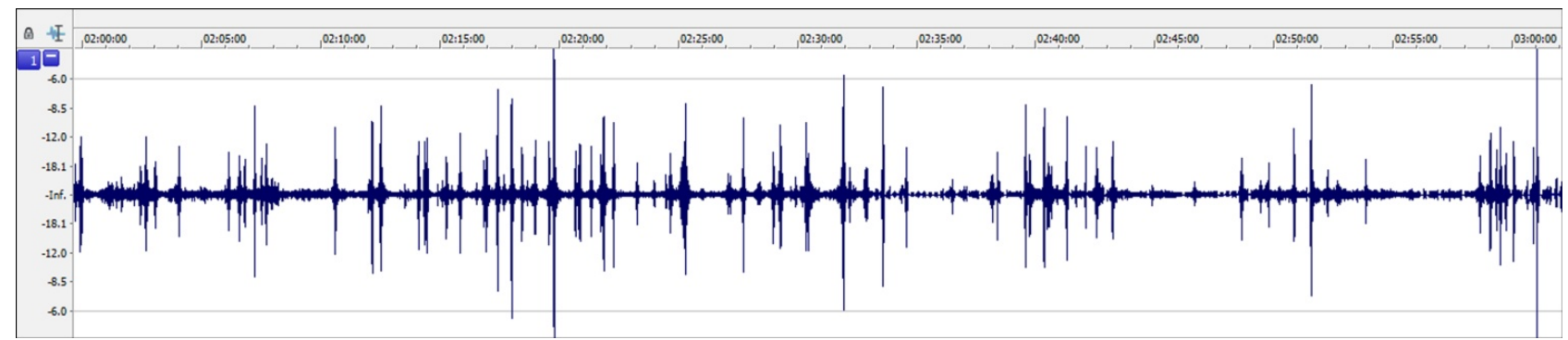

Figure 4. Soundscape map, 2:00 a.m.-3:00a.m., 23 August 2013 (5318'10.1"N 258'00.9"W).

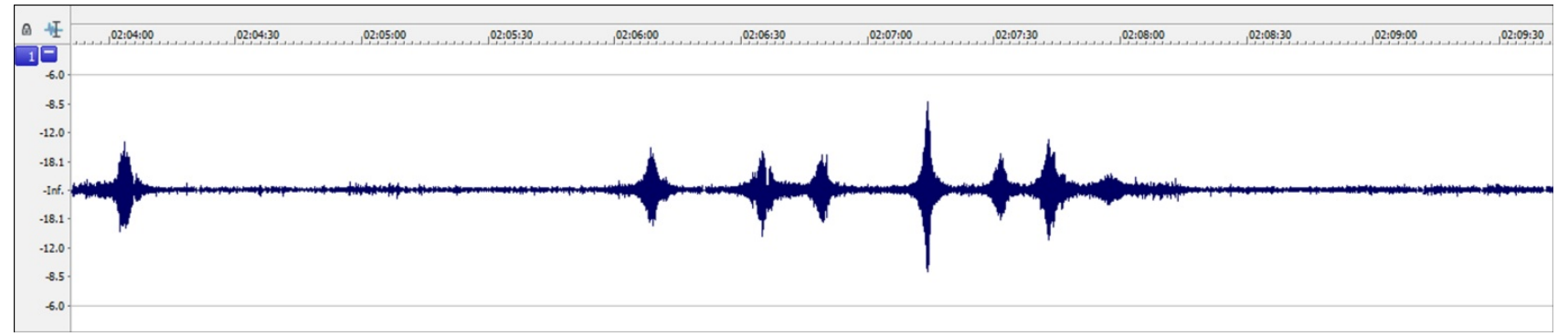

Figure 5. Soundscape map (detail), 2:04 a.m.-2:10a.m., 23 August 2013 (53¹8'10.1"N $\left.2^{\circ} 58^{\prime} 00.9^{\prime \prime} \mathrm{W}\right)$. To listen to soundscape see: [42] (recording best heard with headphones).

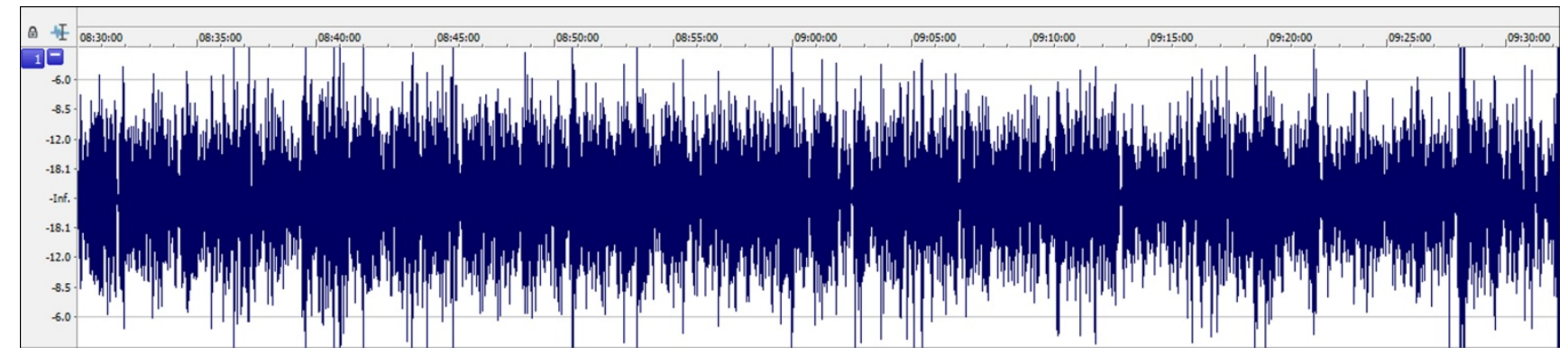

Figure 6. Soundscape map, 8:30 a.m.-9:30a.m., 23 August $2013\left(53^{\circ} 18^{\prime} 10.1^{\prime \prime N} 2^{\circ} 58^{\prime} 00.9^{\prime \prime}\right)$.

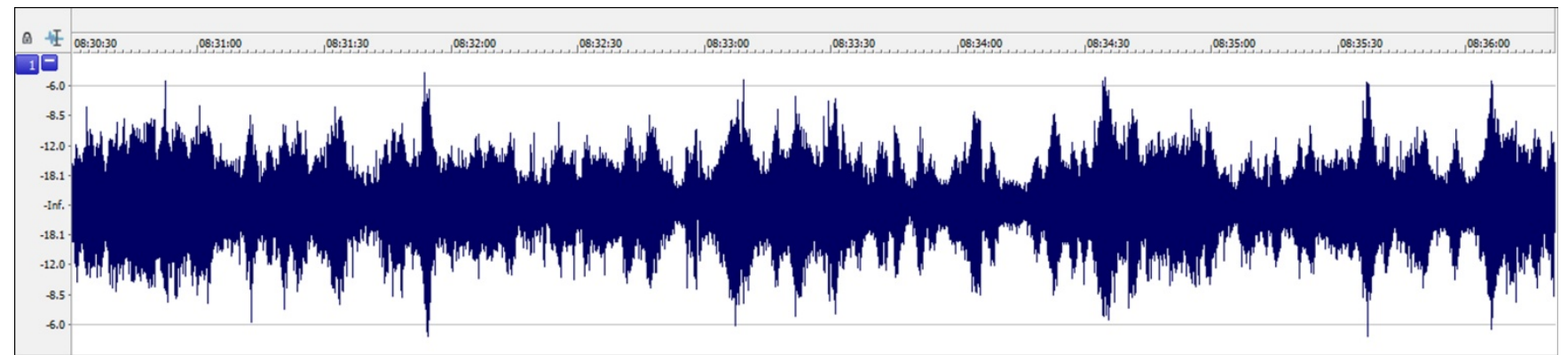

Figure 7. Soundscape map (detail), 8:30 a.m.-8:36a.m., 23 August 2013 (53¹8'10.1"N $\left.2^{\circ} 58^{\prime} 00.9^{\prime \prime} \mathrm{W}\right)$. To listen to soundscape see: [43] (recording best heard with headphones). 


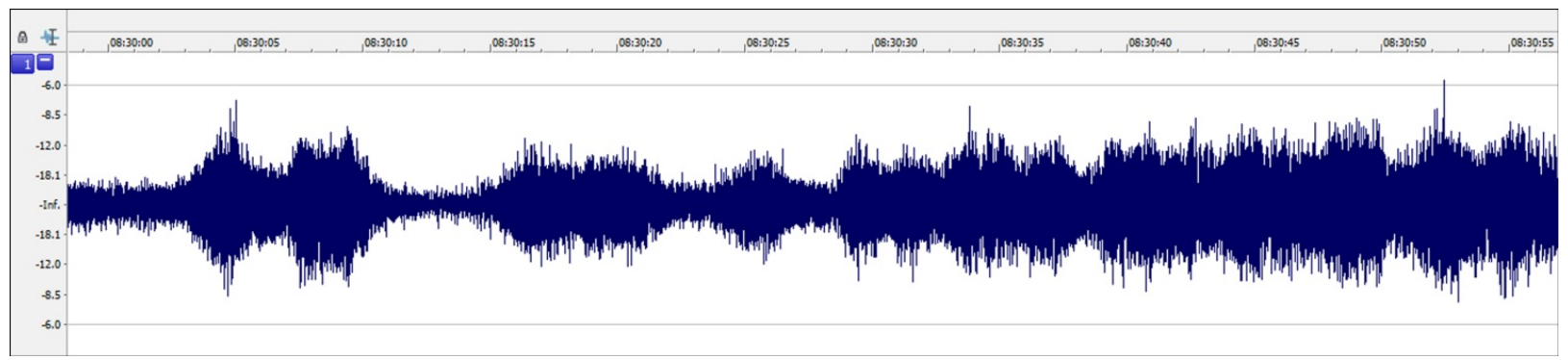

Figure 8. Soundscape map (detail), 8:30 a.m.-8:31a.m., 23 August 2013 (53¹8'10.1"N 258'00.9"W).

If we compare Figures 4 and 6 (2:00 a.m. to 3:00 a.m. and 8:30 a.m. to 9:30 a.m., respectively), the difference in the intensity of rhythm is stark and vivid, not all that surprising given that one of the maps corresponds with the height of morning rush hour. From one vantage point, then, the rhythms of the road represent a chronometric reading of a purely functional, processual and utilitarian space. From another, however, and one more in keeping with the idea of the island as an embodied and experiential space, these representations map onto an interiorized world of which, as "rhythmanalyst", I am both monarch and intrepid explorer. Revisiting the space-time of the island through sound, the images can quite readily be re-imagined as electroencephalographic readings of brain wave activity. Between 2:00 a.m. and 3:00 a.m. it is a landscape shaped as much by gaps and lacunae as the indicative verticality of "events". The mind is wound down and given over to the contemplative or somnolent flux of phenomena that, come morning, has succumbed to the more fevered density of ambient activity. By contrast, between 8:30 a.m. and 9:30 a.m. there is little in the way of horizontal "space" in which the mind can wander. Instead we are thrown headlong into the fray of a dense conurbation: a surging cluster of individuated time that barrels across the page like a juggernaut.

In his "previsionary portrait" of the rhythmanalyst, Lefebvre presents us with a figure who "listens - and first to his [sic] body; he learns rhythm from it, in order consequently to appreciate external rhythms. His body serves him as a metronome" ([2], p. 19). The metronomic function of the researcher's situated body is a central methodological component that marks out her or his practice from that of, say, the surveyor or topographer. The body feels for rhythm, a process that allows for the spiralling out of embodied time to the spatiotemporal precincts of the wider social world, a conjunction that can be felt in either resonant or dissonant terms (or, as is more likely, both). Lefebvre goes on to remark that the body produces a "garland" of rhythms: "the surroundings of bodies, be they in nature or a social setting, are also bundles, bouquets, garlands of rhythms, to which it is necessary to listen in order to grasp the natural or produced ensembles" ([2], p. 20, emphasis in original). The time domain images, especially those extracted from sound recordings made during the day, might themselves be likened to garlands inasmuch as they represent a bundle of temporal moments "strung together" in the fashion of what Lefebvre describes as "an aesthetic arrangement" ([2], p. 20). Garlanded by rhythm on all sides, my time on the island was not entirely my own insofar as my embodied self was in part a composite assemblage of the time of others. But equally, by adorning myself in the garlanded rhythms of the motorway I was able to cultivate and fashion my own spatiotemporal corporeality. Bringing into sharper relief the very otherness of the rhythms that defined the space-time of my island dwelling, the marooning helped make possible a time-unto-myself: an experiential "time out" that provided the space for a creative re-ordering or re-assemblage of the space-time rhythms of an otherwise mundane 
roadscape. Viewed methodologically, the function of the body in this non-place setting is, therefore, that of a rhythmanalytical apparatus or interface: the body as a site of spatiotemporal praxis.

\section{Road to Nowhere: Beginnings}

If the discussion has thus far centred more squarely on temporality and rhythm in terms of an embodied mapping of the motorway island, no less important are considerations of its material geographies and why it is that such a topographic anomaly is there at all. However seductive it may be to think of this space as existing "outside" of the quotidian trammels of history (as if a "bubble" of utopic non space that has somehow fallen between the cracks of Euclidean social reality), a more prosaic reflection would be to cast attention on the historical geography of this stretch of the M53 motorway and the circumstances surrounding the island's formation. Refer to any map showing the area just to the west of Junction 5 on the M53 and it is not difficult to infer an obvious design intent on the part of the motorway engineers despite the fact that these plans never came into fruition. A provisional history can be gleaned from even the most cursory cartographic scrutiny. On a satellite image, for example, a curious oblong feature seemingly protruding from the island on the south side of the northbound carriageway has obvious affinities with the island topography in ways that cannot fail to pique geographical interest (Figure 9). If we turn to a detailed Ordnance Survey (OS) map of the island the relationship between the two features is rendered all the more apparent (Figure 1). That this island protuberance is the result of an aborted motorway design can be confirmed by reference to a 1970s OS map published when the M53 was still under construction. The oblong is now clearly understood as being part of a planned extension of the motorway that was to have continued in a south-westerly direction (Figure 10). The clincher is determined by reference to one final map showing the newly constructed motorway and road network around the Junction 5 exit (Figure 11). The triangular shape that defines the area that has since come to form the island is made up of what were to have been two slip roads exiting the motorway that would eventually link up with the M531 that bypassed Ellesmere Port to the east. The carriageway of the M53 was to have continued south thus forming what is now the bulk of the island terrain as well as the adjacent patch of land. What were to be the slip roads are now the south- and northbound carriageways of the M53, which continues southeast along the route of the former M531. In other words, to position oneself on the island is quite literally to be on a road to nowhere. A more visible monument to this short-lived plan was a flyover bridge that, until its demolition in the early 2000s, spanned little more than the width of the motorway's northbound carriageway (Figure 12). 


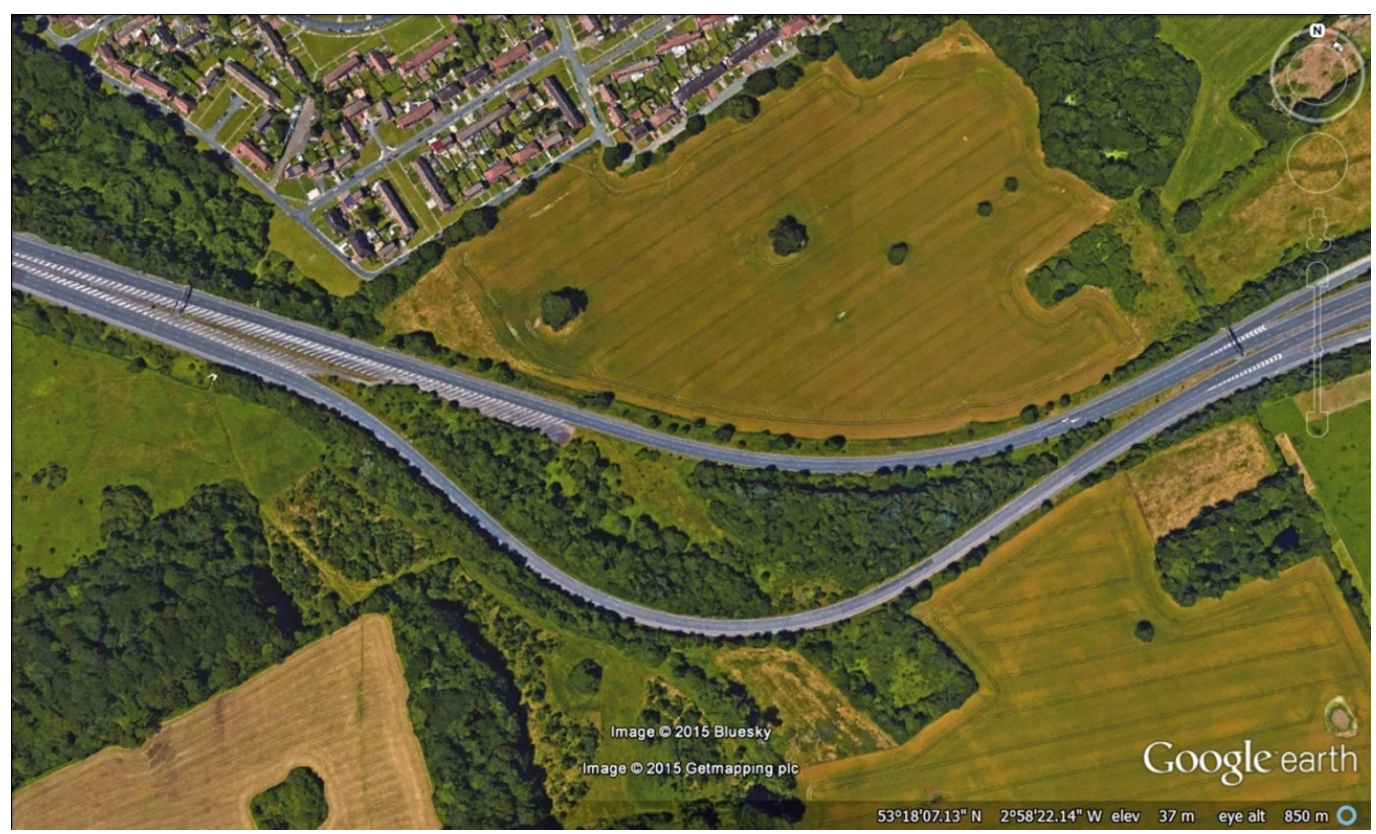

Figure 9. Aerial view of island (Map data: (C) Google, Bluesky, Getmapping plc [2015]).

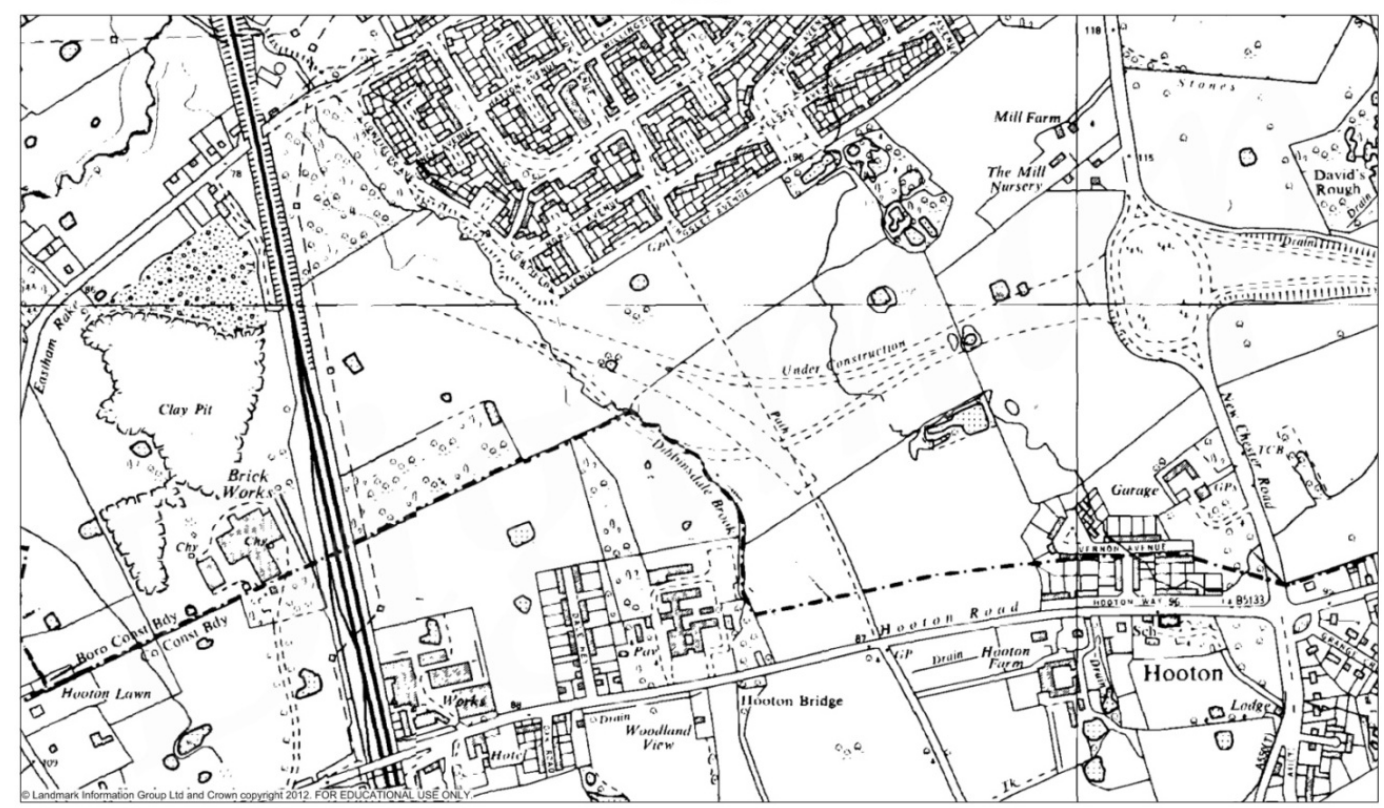

Figure 10. 1970s OS map of island (under construction) and surrounding area (1:7500) (Map data: (C) Crown Copyright and Database Right [2013], Ordnance Survey (Digimap Licence)). 


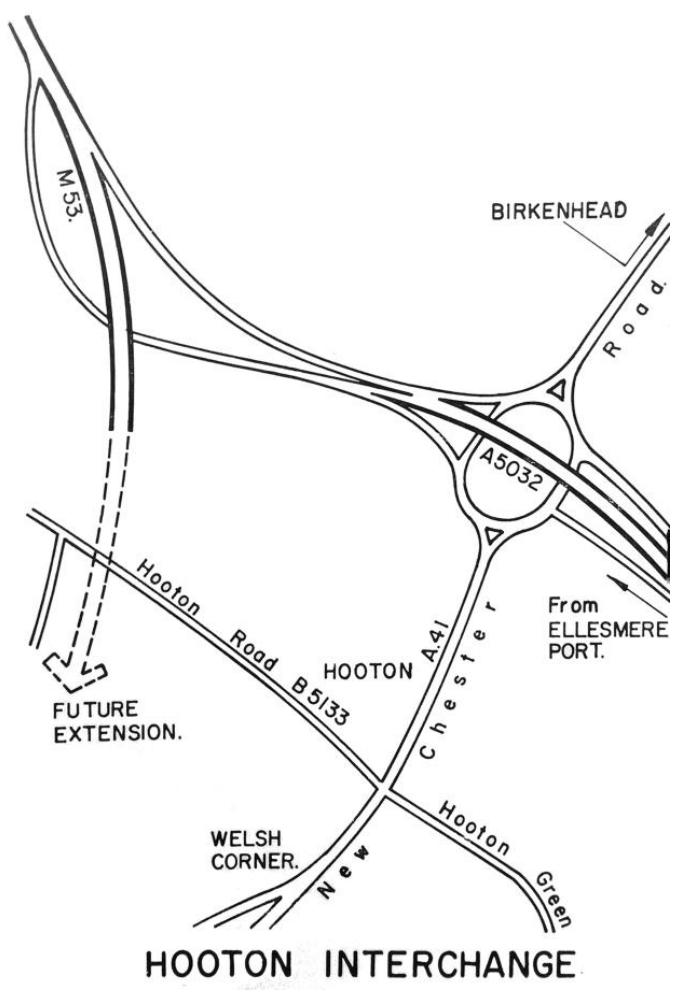

Figure 11. Illustrated map showing proposed southbound M53 extension. (Department of the Environment [45], (C) Crown Copyright (n.d.)).

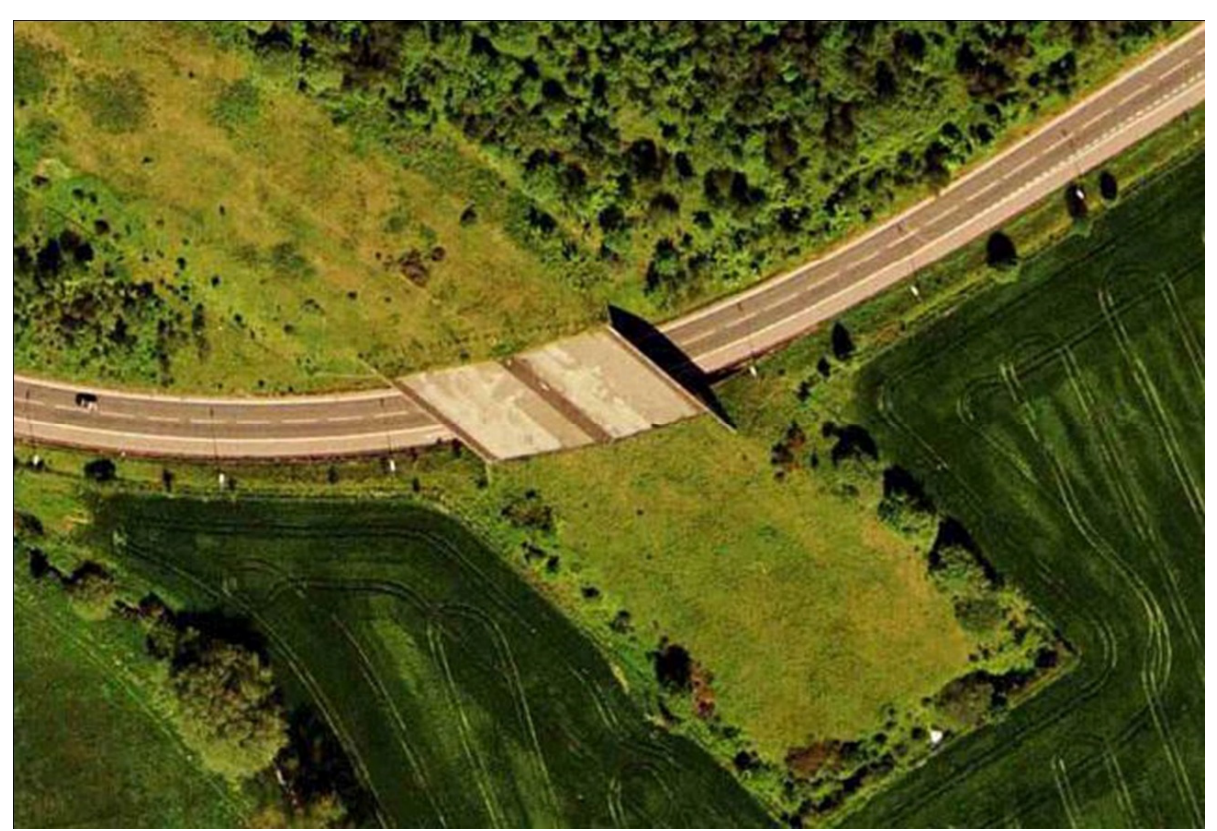

Figure 12. Aerial view showing motorway bridge built as part of proposed southbound M53 extension, c. 2000 (Map data: C wikiwirral.co.uk [2008]).

Work on construction of the M53 Mid-Wirral Motorway began in 1969 and was carried out in various stages until 1982 when the last section was opened, extending the motorway to the outskirts of the city of Chester. The M531, which had been extended to join up with the M56 North Cheshire East-West Motorway, was completed in 1981 and would became part of the M53 as it exists today, 
which runs along the spine of the Wirral from the Kingsway (Mersey) Tunnel in the north to the A55 North Wales Expressway near Chester in the south ([46], pp. 311-13). In their report published in 1966, the Consulting Engineers commissioned by the Ministry of Transport to carry out a location study for the new motorway recommended that the route be extended south to the interchange at Dunkirk with the A5117. This would have linked with a newly extended M56, but also would have provided a faster route for traffic bound for North Wales along the A494 ([47], p. 10).

As already mentioned, the M53 is a road that I use often as part of my regular journey from North Wales, where I live, to my place of work in Liverpool. Junction 5, which is near to the location of the island, is the point at which I enter and exit the motorway. Had the proposed southbound extension gone ahead this would have been the route I would have routinely taken (cutting a good ten minutes off my commute time in the bargain!). Given this, perhaps my "islandness" [48] might be construed as nothing more than a performative work-through of a latent geography that was destined not to be consummated (a utopian imagining sprung from an unrealized sense of auto-mobile satisfaction). However, a more likely rationale would be one that sought to join the dots between an experience of motorway "driving space" [20] and the "off-road" geographies that, over time and repeated iterations, have become firmly imprinted on my cognitive and affective map of the M53 as an everyday landscape. Because the distance travelled along the motorway is relatively short (the M53 is only 19 miles from beginning to end) it has rarely felt as monotonous a driving experience as that encountered on, say, the M6, or other parts of Britain's motorway network. Edensor's observation that "confrontations with forms of otherness [such as fantasies, disruptions, lines of flight, sensual intrusions]...disrupt routinized experience and practice, throwing into sharp relief constructions of normative automobility" ([29], p. 155) does not adequately take into account the extent to which such disruptions are themselves part of routinized and habitual experience. The question: "How might routine commutes by car on the motorway be defamiliarized?" ([29], p. 155) can thus partly be answered by pointing to the ways that commuters routinely defamiliarize their surroundings through recourse to the flights of imagination, disruptions, sensualities, and so on that are part and parcel of the negotiation of these and other everyday landscapes. To reiterate the argument made earlier: non-places contain within them the potentiality of their own negation; motorways, on account of the very mundanity and featurelessness that Edensor's argument sets out to counter, are affective spaces given over to the "commingling" ([35], p. 12) of the self with the entropic energies of a landscape in flux.

One of the (de)familiarized features of the motorway which I found myself becoming ever more entangled with was the verdant mantle of trees that defined the territory that I only later realized to be an island. Approaching along the southbound carriageway, the apparently pointless margin of hatched road markings that flank the northern stretch of the island, along with a red and white "road closed" sign erected to (presumably) prevent cars from stopping or using the road markings area as an additional lane, were what first drew my attention (Figure 13). As subsequent journeys and more attentive rubbernecking would make clear there is more to this landscape than meets the eye. For a start, much of the island terrain remains unlandscaped; it is a pocket of land otherwise untroubled by the upheaval of road construction, as if it had somehow managed to hold off the territorialising march of the bulldozer and excavator and the contractors had resignedly accepted that they would have to work around it instead. As we have already seen, aerial views and maps allow us to clearly make out 
exactly where the excavatory incision for the road-that-was-not-to-be had been made. But either side of this cleft remains a dense thicket of trees and topographically uneven terrain that thumbs its nose at the uniformity of the surrounding road. This was a landscape that had the appearance of concealing a story that it had never got around to telling itself. Beyond the piecing together of a truncated history from official archival records, or the online chatter of discussion forums where amateur historians or transport enthusiasts trade local knowledge and geographic speculation ${ }^{6}$, the narrow curve of unkempt (and untouched) greenery offers itself up as the only viable resource from which to extract a semblance of a geographical or archaeological narrative. A hastily thrown glance as I sped by at 60 or 70 miles per hour could only disclose so much.

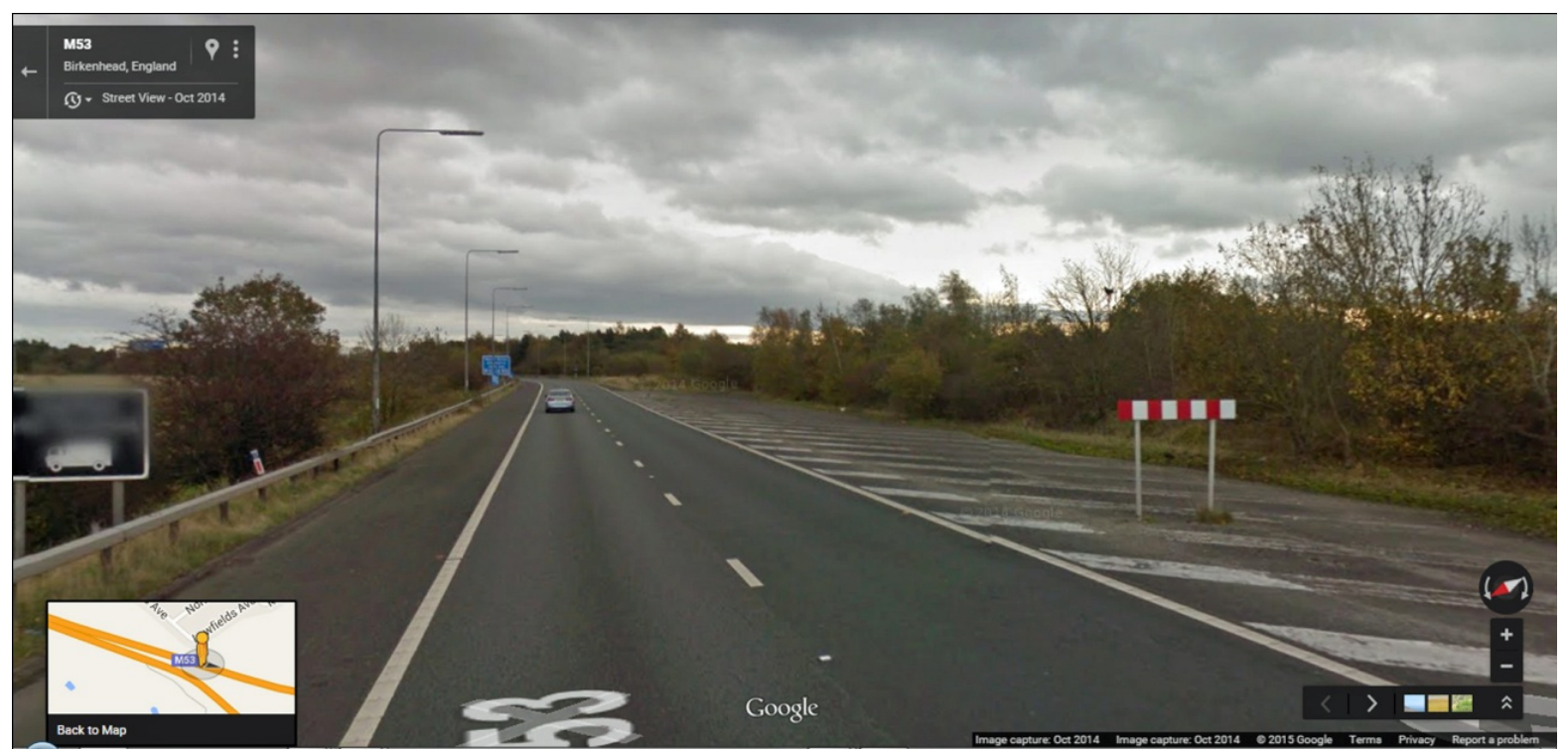

Figure 13. View approaching the island on the southbound carriageway (Map data: (C) Google [2014]).

\section{Making Tracks: Embracing Islandness}

I hacked through dense thicket for a while then saw a ditch leading up/away [providing a route] with less dense obstructions. I hacked a clear path along this, making sure that the path could be easily identified for the return journey. I continued along this as far as I could before hitting an impenetrable wall of bramble and trees. I scrambled up a bank to the left of the "path" and, after some minor hacking, found this led out onto an open "meadow"...

(Field note extract)

After my night spent under the orange-glow canopy of trees to the east of the island (near to the point where I had landed), and the spatial disorientation that marked, come morning, my initial

6 Research into the construction and planning of the M53 motorway was undertaken at Cheshire Record Office in Chester: [49]). Useful information was also obtained from a number of online resources, such as discussion forums focused on the history and heritage of Britain's motorway network [50-52]. 
attempts at exploration, the objective for the second day was to make my way to the western edge (although, in keeping with an internalized directional logic of northbound/southbound, I was still thinking of this in terms of "north"). The journey was one that mostly involved trekking through the interior of the island, away from the perimeter edges and the rush and immediacy of the morning traffic (a concern with being spotted by passing motorists, particularly lorry drivers who had a higher vantage point, meant that the journey "north" offered a welcome opportunity to once again don a cloak of invisibility) (Figure 14).

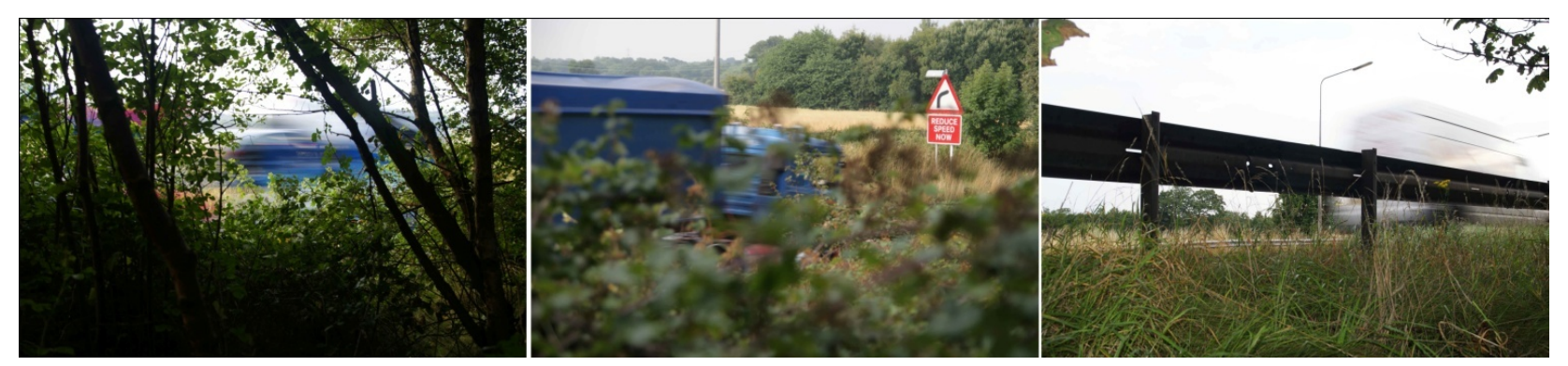

Figure 14. Flow.

The difficulties encountered in navigating those parts of the island that have remained largely untouched by human intervention were compensated by the reward of arriving at the open expanse of grassland which (not inaccurately) I referred to as the "meadow". The meadow represents that area of land that had been carved out by the motorway contractors as part of the aborted plans to extend the route directly south (Figure 15). As my field notes describe,

This open area is comprised of tall grasses, thistles, wild flowers, and a number of crumbling brown-earth ant mounds. Beyond the clearing is another dense mass of trees and brambles, which dips down into a "valley" type area. Beyond that the island flattens and thins out and comes to an end. I walked around to the edge of the last group of trees and could just make out the stripy road markings that mark the start of the island, but it was not possible to see these clearly without being seen by motorists. The clearing area, as it is open, is mostly in full view of the southbound traffic. The meadow/clearing must be the highest point of the island.

(Field note extract)

By the time I reached the meadow it was midday, the sun had fully broken through the intermittent cloud cover, and a light breeze was toying gently with the tall grasses and ragwort. After some time spent photographing and videoing the landscape and flora, I sat for an hour or so soaking up the warmth and the undulant rhythms and succumbing to a feeling of general wellbeing and corporeal detachment. If I had been climbing a mountain this would have been the summit moment: a snatch of well-earned "time out" before the final descent. This part of the island was also the widest, meaning that I was furthest from the motorway than at any point in my residency. Because of this it was possible to get more of a sense of the landscape as existing on its own terms and not as merely an adjunct to the roadscape or as a negative space defined wholly in relation to the motorway. 
An entry in my field notes written at 04:17 a.m., when ensconced in the wooded area that I had made my base for the night, recorded the following observation: Appears to be little in the way of insects or wildlife. Nor, from what I recall, was there much diversity in terms of plant life on this part of the island. It was as if the location's close association with the motorway, just a few feet to the north, had taken its toll on the island ecology and drained it of vim and vitality (something that, up to a point, resonated with my own embodied experience during this period). In the meadow, by contrast, life had all the appearance of being a good deal more abundant. While it would be premature to start imagining some form of utopian settlement eking out an existence on the island's untapped natural and aesthetic bounty, the affective appeal of the meadow does invite reflections on ideas of "islandness" conceived of as a spatial practice oriented in response to the mainline rhythms and spatiotemporal structures of everyday modernity.
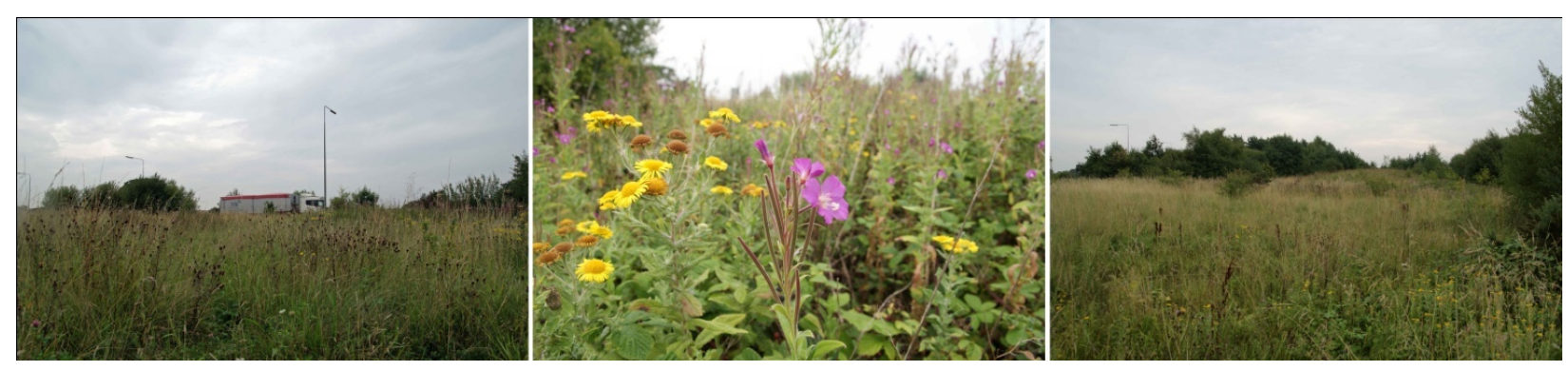

Figure 15. Meadow.

In their self-styled "non representational" approach to the question of island dwelling ${ }^{7}$, Vannini and Taggart argue that "islandness" is best approached not in abstract terms (i.e., "what is an island?") but as an affective experience and practice ("how do you do your island?"). Viewed thus, islandness "changes from a representation inside our heads to a set of tasks unfolding in front of its inhabitants" ([48], p. 235). In other words, the ways in which an island is dwelt upon determines the meanings and shape that make the island what it is: "the life of your island is the sum total of the sensations it gives rise to, the cumulative incorporation of those feelings carved into its soils and shores, and the embodiment of its affective spaces on its dwellers" ([48], p. 236). Although such a formula might conceivably be applied to any type of landscape (it also raises the question of whether a performative/non representational understanding of islandness is necessarily predicated on there being something that topographically/representationally is an island in order for it to be valid) what it does usefully point to is the way islandness is carved out through the different forms of practice, movement and mobility that temporalize the landscape and confer on it the more anthropologically-loaded status of "taskscape".

For Ingold, the concept of taskscape offers a strategically important tool with which to re-think landscape in terms of its fundamental temporality. "[T]he temporality of the taskscape," he suggests,

while it is intrinsic rather than externally imposed (metronomic), lies not in any particular rhythm, but in the network of interrelationships between the multiple rhythms of which the

7 For a critical discussion of perspectives on so-called "non-representational" geographies of place and mobility, and comparisons with approaches developed in phenomenological and existential anthropology, see Roberts and Andrews [53]. 
taskscape is itself constituted....the forms of the taskscape, like those of music, come into being through movement. Music exists only when it is being performed; it does not pre-exist, as is sometimes thought, in the score, any more than a cake pre-exists in the recipe for making it. Similarly, the taskscape exists only so long as people are actually engaged in the activities of dwelling. ([54], p. 197).

If we extend this reasoning to maps (as Ingold himself goes on to do in a subsequent chapter of The Perception of the Environment), and to the process of mapping the embodied landscape/taskscape of the motorway island, then what we might understand as "deep mapping" acquires greater resonance insofar as it helps tease out the temporal dynamics ascribed to a cartographic method that is critically underpinned by an anthropological sensitivity to landscape as a fundamentally social, embodied and lived set of practices. Deep mapping is thus strongly consonant with an idea of "wayfinding": knowledge that is "cultivated by moving along paths that lead around, towards or away from places" ([54], p. 229). As a product of wayfinding, spatial and environmental knowledge is "ambulatory...[in that] we know as we go, not before we go" ([54], p. 230, emphasis in original). Mapping-as-wayfinding unborders the map as a frame or plane of representation. The cartographer-as-wayfinder, by extension, is a fundamentally embodied subject whose field of practice is similarly unbounded and more productively thought of as a meshwork in which she or he is reflexively entangled. Mapping, in this sense, is as much about the embodied self as it is about the space which the cartographer (or spatial anthropologist) is oriented towards as a focus of study and in which s/he dwells [55].

Dwelling in the midday sun of my island meadow, the less fevered rhythms of the road now more of a background tapestry of sound than in-your-face maelstrom, the landscape I had at my disposal was one that to a large extent had been willed into being. Even now, as I (re)construct the performative map of my island imaginary, the iteration of its fictive geographies is such that whatever might be gleaned in terms of "islandness" is nothing but the residual and contingent product of my being-there (an islandness, in other words, that can only ever be "my" islandness). Much of what would have passed through my consciousness, like the evanescent flow of traffic around me, has long since faded into oblivion. The traces that remain — whether hastily scribbled field notes, digital captures of various description, or memories that have coalesced into renderable form-have provided the basis for a tenuous archaeology from which I have crafted the outline of a narrative journey, the performance of which has given shape and substance to a "place" that is otherwise not a place (or that is a non-place, to affirm the negative). If I remove myself from the equation there is no island to speak of, merely an inconsequential pocket of land tucked between two motorway carriageways (two slip roads that were destined not to be) which, for much of the four decades or so it has existed, has probably mustered little if any human interest. It is negative space in the same way that the area beneath objects such as chairs or tables, made concrete (literally so) in work by the artist and sculpture Rachel Whiteread, is negative space. It is not that the space is not there but that it is through the intervention of the artist (or in my case the autoethnographer or spatial anthropologist) that what is not not there acquires a rudimentary form. To dwell in such a space is therefore to both conjure and embrace this form. Islandness is culled from abstraction in the same way that an imaginary is culled from the imagination. In Dialectic of Duration, Bachelard remarks that "The story of a journey is a function of its 
geography" ([4], p. 89). The geography of the island is that which, in the first instance, makes it an island (the liquid space of the motorway replacing that of water). But the island's geography is also what makes it an island in the narrative sense (a story and performance, an academic fiction). Islandness is the story of a journey. Moreover, it is in the journey that we trace and retrace what it is that islandness might conceivably delineate at any given juncture.

Mapping the islandness of the island is a process of, firstly, making tracks. These are laid down in the act of walking, the gleaning of digital ephemera (images, audio, geospatial tracks ${ }^{8}$ ), and the embodied immersion in a space that is ordinarily marked out in terms of its placelessness and abstraction. The follow-through is the re-tracing (re-making) of these tracks and moulding them into a bricolage or assemblage, the function of which is to convey a spatial story that maps onto an embodied sense of place: the being-there-ness of my island dwelling. The task of re-tracing/re-making is constituted in the process of writing-up. In this respect the relative "depth" of mapping is a measure of just how vivid or impressionistic the performative space of islandness actually is in terms of a cartographic imaginary. As an autoethnographic narrative, the locative properties of the text are such as to situate myself within a representational space that both frames my "being-there" (the recounting of a journey in the etymological sense of a "day's work or travel" (from jornee in Old French)) and creates a setting (a mise-en-scène) in which to explore the imbricated rhythms and temporalities by which "islandness" is set adrift and plugged into a wider matrix of space, time, and everyday mobility.

As a purely geo-locative spatial story — a meshwork of lines digitally inscribed on a map —islandness can be textually reconstructed in the form of an itinerary or journey: a traversing of physical space. But this too can be shown to register the pull effect of centrifugal space, the affective force of the motorway's hyper-mobile and "placeless" environment threatening to destabilize an otherwise Euclidean pattern of lineation. The maps shown in Figures 16-19 each chart — up to a point — the route I followed throughout my time on the island. I digitally recorded the tracks of my journey using two separate devices: a GPS-enabled tablet computer and a Garmin eTrex GPS receiver. Both sets of tracks are represented on the map at scales of 1:5500, 1:1500, 1:100, and 1:10. In Figure 16 the whole route is visible, from the starting point at a residential street called Dale Hey where I had parked my car, to the point where I crossed over the motorway (a journey which in itself was by no means straightforward, having been determined as a result of two prior recce, or reconnaissance, visits), and then my meanderings across the island itself. The return journey and crossing followed the same route.

8 Digital content (audio soundscapes and video) can be accessed via hyperlinks provided in note 5 above [42-44]. 


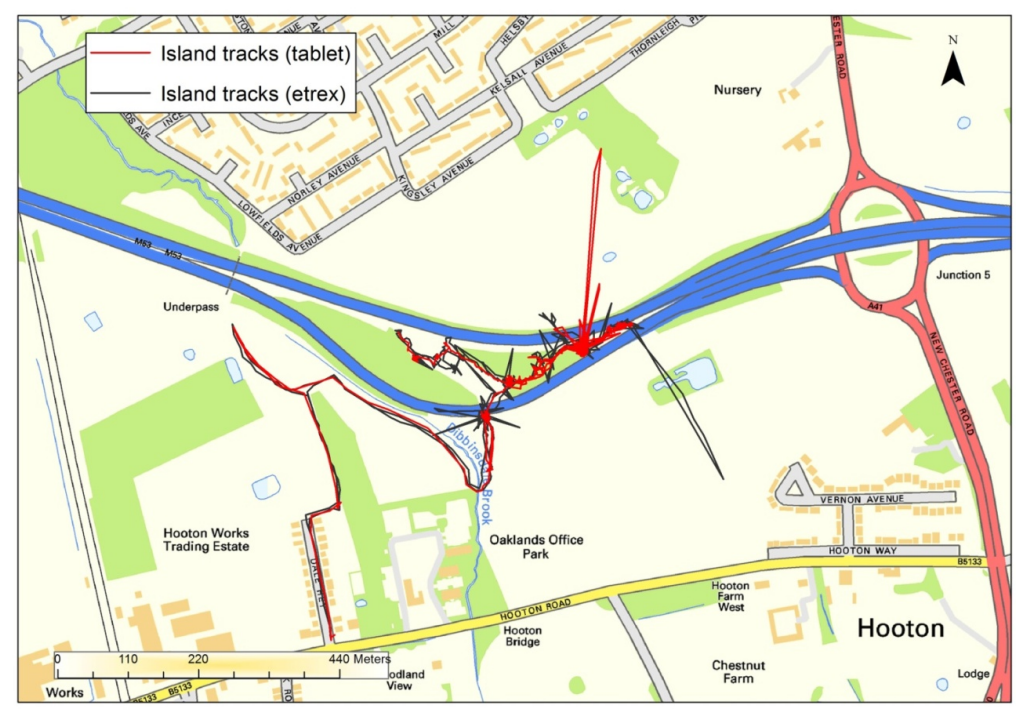

Figure 16. Map showing GPS tracks of island field visit, 22-23 August 2013 (1:5500) (Base map data: C) Crown Copyright and Database Right [2013], Ordnance Survey (Digimap Licence)).

However, where the GPS signals dropped out momentarily en route there are several spikes that are visible, the most prominent being the red (tablet) lance-like feature jutting northwards and its black (eTrex) counterpart pointing south-east. If we zoom in to the next scale (Figure 17) we start to get a clearer picture of just how erratic and undisciplined the track lines in fact are. Zoom in again (Figure 18) and a thick knot of red lines reveals a quite alarming degree of agitated movement around what is less than a 100 square meters area to the east of the island. This surely cannot be an accurate representation of my actual spatial mobilities. If it is, then I am at a loss to account for the frenetic rhythms being tramped out or why it was I thought that such a complex and baffling pattern of movement might have been necessary. If we zoom in one final time (Figure 19), then it is almost as if we are entering a different spatio-temporal dimension entirely. If evidence were needed that, at a micro level, some other, wholly unaccountable form of spatial activity was being tracked then this is it. The area shown on the map is little more than five square meters. The geometric complexity revealed at this scale maps a web of mobility that resembles nothing that is corporeally human. In fact, the points on or near the island where these disturbances mainly seem to occur correspond with those where movement was minimal, such as the location at the edge of the motorway where I waited to cross over to the island. The dense mass of tangled lines to the east of the island marks the location where I had camped for the night. If these patterns represented the tracking of movements in space then they were not any that I could convincingly lay claim to.

Whatever technical quirks or environmental anomalies these tics and spikes might be attributed to lies beyond the scope of the present discussion. However, given that they tended to occur at locations where I was mostly stationary it is hard not to equate them with the affective traffic of thoughts, sensations, rhythms, reveries, flows, transmissions, and general mental meanderings that arise when the body comes to rest. Trading the "taskscape" of the purposive trek (track lines with few aberrant deviations) for the unfettered space of the imagination (track lines that display no discernibly rational spatial logic), the body's entanglement with this meshwork of lines opens it up to a qualitatively 
different set of mobilities. As with the soundscape maps discussed earlier, rhythms captured as a result of empirical methods of environmental data capture function instead as detourned mappings that project a purely experiential and embodied sense of space. The pregnant liminality of this space allows for the steady accretion of temporal topologies ("time out") that deterritorialize and "garland" the embodied self. The centrifugal pull of the motorway exerts a force that suffuses almost every facet of island dwelling, even - or rather especially_in those moments when consciousness takes flight far beyond the space-time of the present.

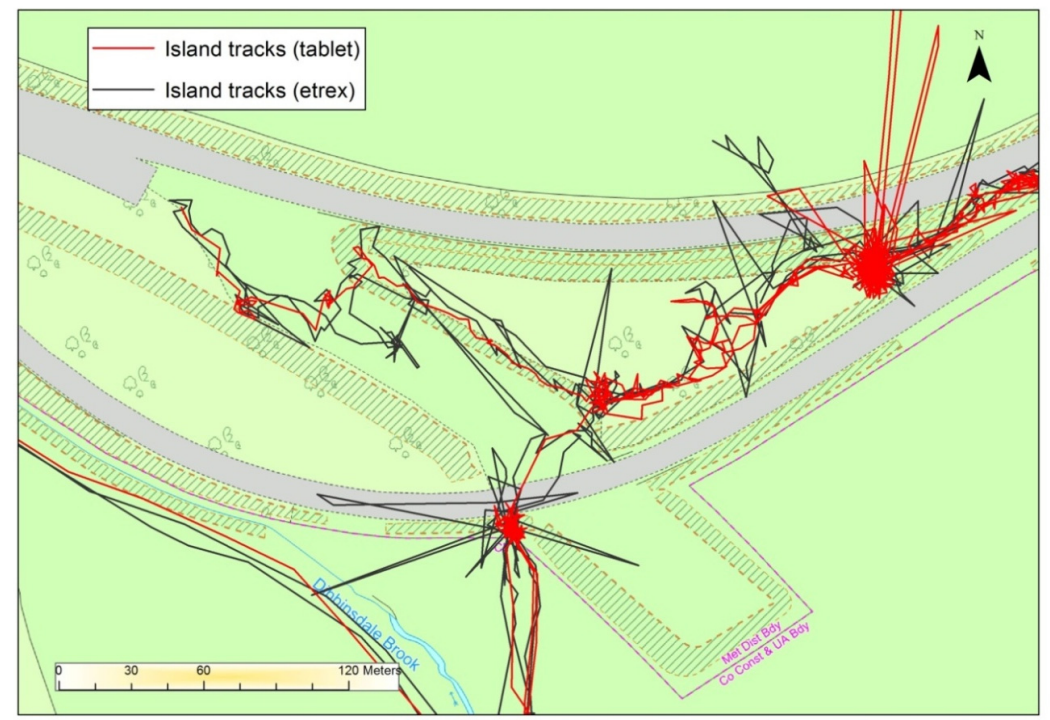

Figure 17. Map showing GPS tracks of island field visit, 22-23 August 2013 (1:1500) (Base map data: C Crown Copyright and Database Right [2013], Ordnance Survey (Digimap Licence)).

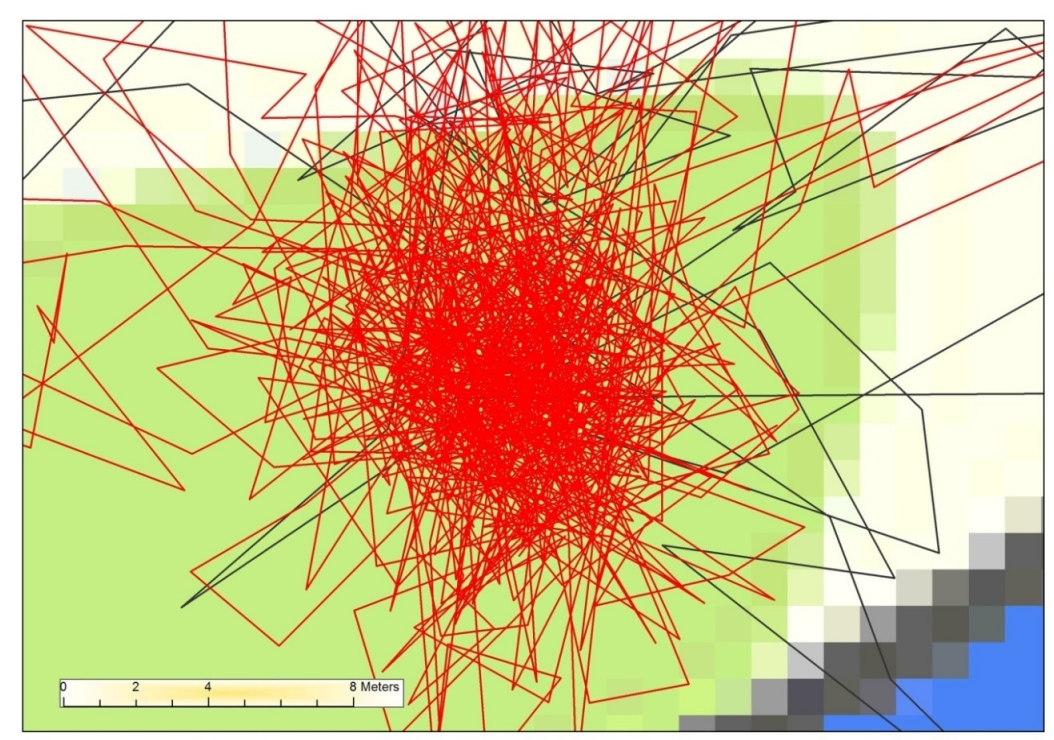

Figure 18. Map showing GPS tracks of island field visit, 22-23 August 2013 (1:100) (Base map data: C) Crown Copyright and Database Right [2013], Ordnance Survey (Digimap Licence)). 


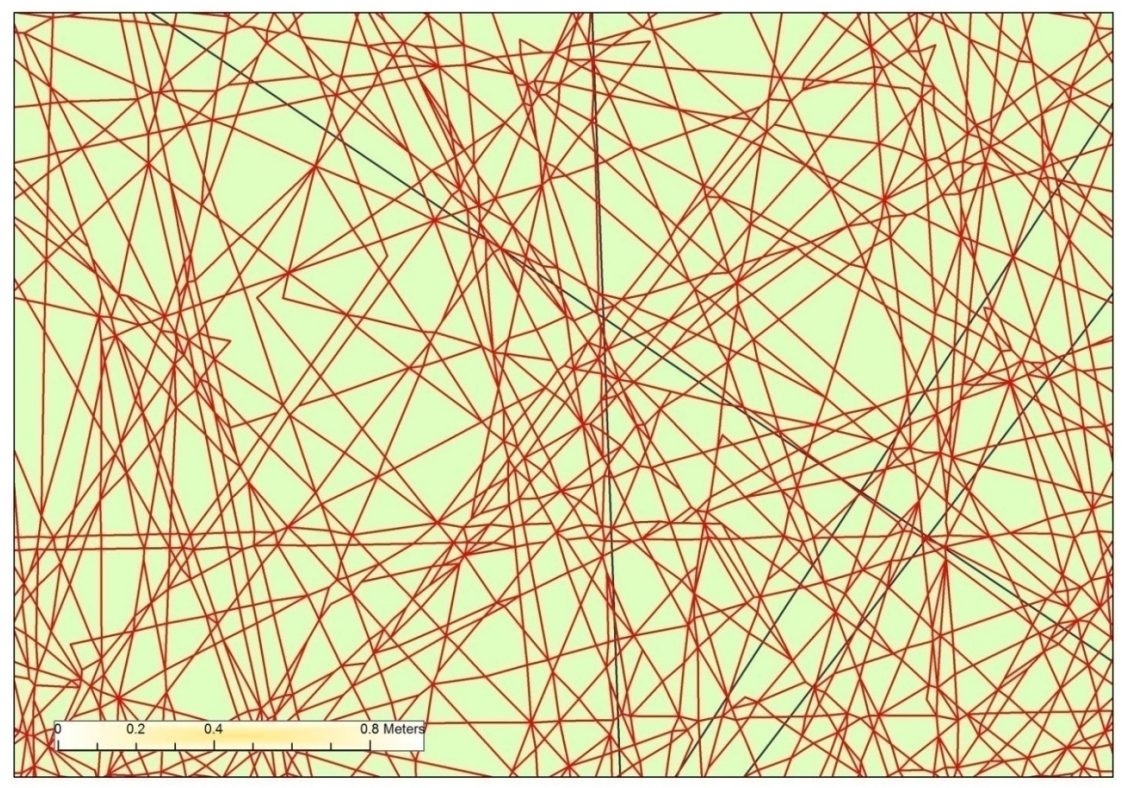

Figure 19. Map showing GPS tracks of island field visit, 22-23 August 2013 (1:10) (Base map data: (C) Crown Copyright and Database Right [2013], Ordnance Survey (Digimap Licence)).

\section{The Rhythm of Non-Places: Exit.}

When it came time to make my departure from the island there was already a palpable shift in rhythmicity, back towards the more routinized temporalities encountered as part of my everyday spatial practice. My crossing back over the carriageway, while executed with the same degree of caution with regard to personal safety, was characterized by a more lackadaisical attitude when it came to being seen. For some reason this now seemed less important, and as I scrambled back up the embankment that led to the farmland I had crossed over the day before I realized I was in full view of the flow of traffic that had resumed along the stretch of the motorway that skirts the southern flank of the island. Perhaps a feeling of closure and accomplishment had started to kick in. Perhaps my fatigue and aching limbs (not to mention lacerated forearms from all the hacking through undergrowth) had begun to numb the excitement and sense of danger, blunting the edge of the island's former rhythmicity. Perhaps I was just fed up and in desperate need of a shower. Whatever the circumstances, approached in terms of its spatio-temporal rhythms, what makes the island what it is (by which I mean what gives it its "islandness") are precisely those temporal geographies which, upon arrival, disrupt the habitus of self and body, and which, upon exit, are experienced less acutely.

Rhythms, as Edensor observes, "are essentially dynamic, part of the multiplicity of flows that emanate from, pass through and centre upon place, and contribute to its situated dynamics" ([3], p. 3). The rhythms that make the non-place of the island what it is are, of course, particular to its own situated dynamics. They are also particular to my own situatedness as an embodied subject, rhythmanalyst, autoethnographer, (deep) cartographer, or whatever other label we might choose to affix; the point being that the institutional and individual habitus of the body plays a key part in determining, feeling, intuiting, interpreting, mapping, collecting, assembling, or listening in to the rhythms that constitute the island's observable islandness. Gottschalk and Salvaggio argue that 
non-places exhibit "distinctive temporal parameters that replicate, deviate from, or completely subvert those that typically organize everyday life" ([56], p. 16). While this is borne out by the analysis presented in this study, the timbre and rhythm that makes these temporal parameters distinctive are by no means uniform. The distinctiveness of non-places is not just on account of their constituent temporalities, but also of their heterogeneity. Although, by definition, non-places lack the social and symbolic embeddedness of anthropological places (and hence why they are typically defined in terms of their lack of heterogeneity and identity), when interrogated with the depth and rhythmanalytical precision required to draw out the temporal affects of these spaces, or, when recognising that "the soundscapes of non-places are also important stimulators of movement, interactions, and subjectivities" ([56], p. 27, emphasis in original), the extent to which there is often a distinctiveness and heterogeneity to speak of becomes that much more apparent.

In this respect, a titular focus on the "rhythm of non-places" should not be construed as an attempt to refine a spatial taxonomy to which I am ascribing a transferable set of "defining" characteristics. Such an objective would be almost as reductionist and questionable as that which set about exploring the "rhythm of places". Which places? When? Whose rhythms? How are they measured? To what ends? These are all questions that can just as readily be posed of non-places. Instead of subscribing to an excessively rigid application of the concept (at the expense of fine-grained, ethnographic and performative insights) a more instructive approach is to acknowledge the dialectical configuration that makes spaces such as a motorway island what they are in relation to places that are routinely encountered (and thus more likely to be invested with symbolic meaning and structures of identity). The question that is jostling for attention is not what makes places non-places (a rather well-trodden and near-exhausted line of enquiry) but rather what it is that makes non-places places. To which, of course, the provisional answer is: people.

In epistemological terms, the task of populating non-places is one that informs the necessary (if still nascent) development of a spatial anthropology; in other words, a closer degree of engagement with those who move through, inhabit and produce such spaces. By extension, methodologically the task becomes one of embracing ethnographic and autoethnographic approaches: populating in the sense of the performative emplacement and direct intervention of the researcher in the field. In my case, this latter extrapolation brings with it a more literal connotation in that I was the population where before there had been none. Autoethnography, and an analytical gaze turned partly inward, becomes the default setting: there simply was no one else on the island - no person Friday - to whom I could turn my attention or share my rhythms. The islandness or liminality I experienced was not, therefore, shaped by a sense of communitas [57] or intersubjectivity [58], but rather by the anonymity and abstraction of the hyper-mobile environment in which I was marooned. In such a setting, my self and my body constitute no less of what counts as the "field" as the taskscapes of the island itself:

The rhythmanalyst calls on all his [sic] senses. He draws on his breathing, the circulation of his blood, the beatings of his heart and the delivery of his speech as landmarks...He thinks with his body, not in the abstract, but in lived temporality. ([2], p. 21, emphasis added).

An enquiry into the rhythms of non-places is, therefore, at the same time an enquiry into the rhythms of the self. Thinking with her body in lived temporality, the rhythmanalyst of non-places maps resonant and dissonant connections with the ambient space-time "noise" around and beyond her 
immediate field setting. Proceeding from the existential and "radically empiricist" [59-61] grounding of a field practice attuned to the micro-sensorial and entangled commingling of lived space and embodied time, the rhythmanalytically-observant anthropologist variously reads, feels, senses, captures, measures, channels, conducts, detourns, visualizes, represents, gives vent to, and ruminates on the rhythms - the lived temporality - in which she dwells. One of the key challenges posed by an anthropology of non-places, however, is finding ways to feed out to (and back from) a wider social and intersubjective field of mobility and practice. In other words, how to go beyond the specifically autoethnographic remit of the research. Again, this hinges on the specificity of the non-place in question. An ethnography centred on, say, an airport [62] or the Las Vegas Strip [56], given the steady flow and throughput of people, would of course offer more opportunities in this regard. For a space such as a motorway island - not the kind of setting one would expect to run into prospective informants - the challenge is that much more difficult.

In this vein, the very last task on my island expedition consisted of fixing a laminated flyer onto a strategically chosen plank of wood. The wood fords a brook that marks a key entry and exit point to and from the island. The flyer features a design logo for the motorway project, which at the time I had been calling "Concrete Island". The flyer also includes the URL of a webpage that provides some basic information about the project along with contact details. This was in fact the last of several (identical) flyers I had erected, all but two of which had been pinned to trees at various locations around the island (Figure 20). As might be guessed, the point of the flyers was to keep open the possibility of contact with anyone who chanced upon these particular locations and who might be willing to be drawn into discussion about their own "being-there" (or, indeed, their own "islandness"). The two flyers I had erected at non-island locations (the border brook and a fence near to the point where I had crossed over the motorway) were unlikely to attract the attention of any casual passer-by. Given the difficulty in accessing these locations whoever stumbled upon the flyers would have to have had some purpose or design that had led them there. While there is the possibility that such a design may extend to their marooning themselves on the motorway island, by the same token it is not inconceivable that the discovery of the flyers (and subsequent retrieval of digital information) might plant the idea of an island visit when no such plan had previously been on the cards. Either way, as at the time of writing there remain no correspondents who have got in touch; I can only conclude that either no one has since ventured along the same route or no one has felt sufficiently interested to want to find out more. ${ }^{9}$

9 A follow-on opportunity in this regard is presented by the open-access nature of this journal article and the accompanying audio-visual content accessible via the social media/video sharing platform YouTube (see [44]). Use of YouTube comments as part of follow-up analyses in an earlier video mapping/spatial anthropology project called "The Bulger Case: A Spatial Story" provided an additional layer of contextual discussion relating to the issues raised by the video-see Roberts [63]. Time will tell whether similar opportunities present themselves in relation to the Concrete Island project. 


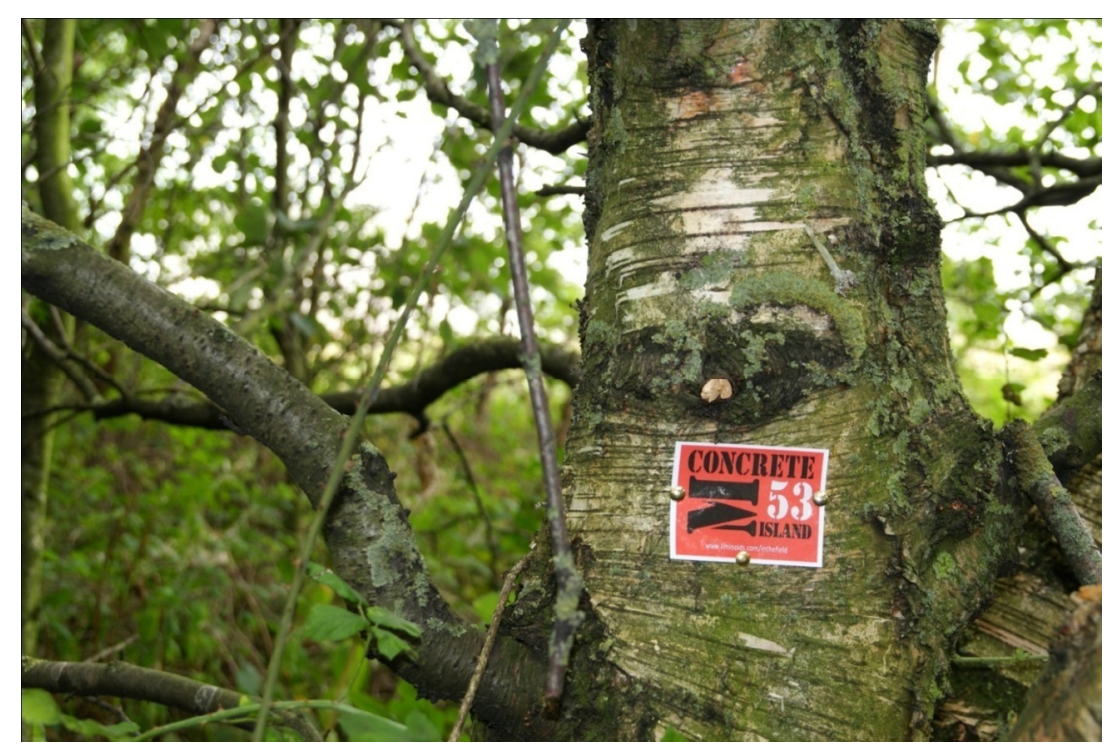

Figure 20. "Concrete Island" project flyer.

It would seem, then, that the island, and the islandness I accrued over the day and night I spent there, are destined to remain mine and mine alone. Perhaps this is as it should be. After all, not only is it illegal to trespass on motorways it is also, self evidently, extremely dangerous. Needless to say this is by no means the kind of project that could be run by a university's research ethics committee for approval. The rationale for this undertaking can hopefully be evinced from the analysis and discussion presented throughout this paper. As a non-place - an unequivocally negative space-it is not the topography and landscape of the island that is of particular import (its constitutive placelessness and absence of human dwelling is for very good reason). Rather, it is all that the island opens up to as an inverted space of abstraction that is of significance: the negation of the negation of place; the non-place as a launch pad of the imagination; the flow and deterritorialisation of the affective body; a creatively "flirtatious" [35] surfing of the utopic; a deep mapping of depthless space. As a negative space, the island, and the islandness it helps foster, is all of these things: a reverse transparency on which to map the meshworks, rhythms and delirious mobilities of late modernity.

\section{Conflicts of Interest}

The author declares no conflict of interest.

\section{References}

1. J. G. Ballard. Concrete Island. London: Fourth Estate, 2014. Original published 1974.

2. Henri Lefebvre. Rhythmanalysis: Space, Time and Everyday Life. London: Continuum, 2004.

3. Tim Edensor. "Introduction: Thinking about Rhythm and Space." In Geographies of Rhythm: Nature, Place, Mobilities and Bodies. Edited by Tim Edensor. Farnham: Ashgate, 2010, pp. 1-18.

4. Gaston Bachelard. The Dialectic of Duration. Manchester: Clinamen Press, 2000.

5. Les Roberts. "The Violence of Non Places." In Tourism and Violence. Edited by Hazel Andrews. Farnham: Ashgate, 2014, pp. 13-31.

6. Meaghan Morris. “At Henry Parkes Motel.” Cultural Studies 2 (1988): 1-47. 
7. Michel de Certeau. The Practice of Everyday Life. London: University of California Press, 1984.

8. Les Roberts. "Utopic Horizons: Cinematic Geographies of Travel and Migration." PhD thesis, Middlesex University, 6 July 2005. Available online: www.liminoids.com/Les Roberts_PhD_ 2005.pdf (accessed on 30 July 2015).

9. Les Roberts. “'Welcome to Dreamland': From Place to Non-place and Back Again in Pawel Pawlikowski's Last Resort.” New Cinemas: Journal of Contemporary Film 1 (2002): 78-90.

10. Hazel Andrews, and Les Roberts. "Introduction: Re-mapping Liminality." In Liminal Landscapes: Travel, Experience and Spaces In-between. Edited by Hazel Andrews and Les Roberts. Abingdon: Routledge, 2012, pp. 1-17.

11. Marc Augé. Oblivion. Minneapolis: University of Minnesota Press, 2004.

12. Hazel Andrews, and Les Roberts, eds. Liminal Landscapes: Travel, Experience and Spaces In-between. Abingdon: Routledge, 2012.

13. Hazel Andrews, and Les Roberts. "Liminality." In International Encyclopedia of the Social and Behavioral Science. Edited by Neil J. Smelser and Paul B. Baltes. Oxford: Elsevier, 2015, pp. 131-37.

14. Bjørn Thomassen. Liminality and the Modern: Living Through the In-Between. Farnham: Ashgate, 2014.

15. Marc Augé. Non-Places: Introduction to an Anthropology of Supermodernity. London: Verso, 1995.

16. Mimi Sheller. "Automotive Emotions: Feeling the Car." Theory, Culture and Society 21 (2004): 221-42.

17. Iain Borden. Drive: Journeys through Film, Cities and Landscapes. London: Reaktion, 2013.

18. Nigel Thrift. "Driving in the City." Theory, Culture and Society 21 (2004): 41-59.

19. Peter Merriman. "Driving Places: Marc Augé, Non-places, and the Geographies of England's M1 Motorway." Theory, Culture and Society 21 (2004): 145-67.

20. Peter Merriman. Driving Spaces: A Cultural-Historical Geography of England's M1 Motorway. Oxford: Blackwell, 2007.

21. Edward Dimendberg. Film Noir and the Spaces of Modernity. London: Harvard University Press, 2004.

22. Iain Sinclair. Lights Out for the Territory. London: Penguin, 2003.

23. Henri Lefebvre. The Production of Space. Oxford: Blackwell, 1991.

24. Iain Sinclair. London Orbital: A Walk around the M25. London: Penguin, 2003.

25. Nick Papadimitriou. Scarp. London: Hodder \& Stoughton, 2012.

26. Margaret Morse. "An Ontology of Everyday Distraction." In Logics of Television: Essays in Cultural Criticism. Edited by Patricia Mellencamp. Bloomington: Indiana University Press, 1990, pp. 193-219.

27. Simon Ward. “'Danger Zones': The British 'Road Movie' and the Liminal Landscape." In Liminal Landscapes: Travel, Experience and Spaces In-between. Edited by Hazel Andrews and Les Roberts. Abingdon: Routledge, 2012, pp. 185-99.

28. Michael Bracewell. "Fade to Grey: Motorways and Monotony." In Autopia: Cars and Culture. Edited by Peter Wollen and Joe Kerr. London: Reaktion, 2002, pp. 288-92. 
29. Tim Edensor. "M6-Junction 19-16: Defamiliarizing the Mundane Roadscape." Space and Culture 6 (2003): 151-68.

30. Peter Osborne. "Non-places and the Spaces of Art." The Journal of Architecture 6 (2001): 183-94.

31. Louis Marin. Utopics: The Semiological Play of Textual Spaces. Atlantic Highlands: Humanities Press International, 1984.

32. The Guardian. "Deadly fantasist." Available online: http://www.theguardian.com/theguardian/ 2001/jan/13/weekend7.weekend1 (accessed on 18 September 2015).

33. Les Roberts. Film, Mobility and Urban Space: A Cinematic Geography of Liverpool. Liverpool: Liverpool University Press, 2012.

34. Chris Lukinbeal, and Leo Zonn, eds. "Cinematic Geographies.”GeoJournal 59 (2004): 247-337.

35. David Crouch. Flirting with Space: Journeys and Creativity. Farnham: Ashgate, 2010.

36. Tim Edensor. "Commuter: Mobility, Rhythm and Commuting." In Geographies of Mobilities: Practices, Spaces, Subjects. Edited by Tim Cresswell and Peter Merriman. Farnham: Ashgate, 2012, pp. 189-203.

37. Benjamin Fraser. Toward an Urban Cultural Studies: Henri Lefebvre and the Humanities. New York: Palgrave, 2015.

38. Marc Augé. "Roundabouts/Yellow Lines." In Autopia: Cars and Culture. Edited by Peter Wollen and Joe Kerr. London: Reaktion, 2002, pp. 293-95.

39. Paul Virilio. Negative Horizon: An Essay in Dromoscopy. London: Continuum, 2005.

40. Giuliana Bruno. Streetwalking on a Ruined Map: Cultural Theory and the City Films of Elvira Notari. Princeton: Princeton University Press, 1993.

41. Michael Bull. "Soundscapes of the Car: A Critical Ethnography of Automobile Habitation." In Car Cultures. Edited by Daniel Miller. Oxford: Berg, 2001, pp. 185-202.

42. "Concrete Island sound clip 1." Available online: www.liminoids.com/inthefield/ConcreteIsland soundclip1.mp3 (accessed on 3 August 2015).

43. "Concrete Island sound clip 2." Available online:www.liminoids.com/inthefield/ConcreteIsland soundclip2.mp3 (accessed on 3 August 2015).

44. "Concrete Island video." Available online: https://youtu.be/LP5tQLDc_Vo (accessed on 3 August 2015).

45. Department of the Environment, and North Western Road Construction Unit. M53 Motorway. Chester: Motorway Archive Trust, Cheshire Records Office, n.d.

46. William James McCoubrey. The Motorway Achievement, Volume 3: Building the Network. London: Thomas Telford, 2008.

47. Maunsell and Partners. Report on the Mid-Wirral Road. Chester: Motorway Archive Trust, Cheshire Records Office, 1966.

48. Phillip Vannini, and Jonathan Taggart. "Doing Islandness: A Non-Representational Approach to an Island's Sense of Place.” Cultural Geographies 20 (2012): 225-42.

49. Cheshire Records Office. "Cheshire Archives and Local Studies." Available online: http://archives.cheshire.gov.uk/ (accessed on 17 July 2015).

50. Pathetic Motorways. "M53 Mid-Wirral Motorway." Available online: http://pathetic.org.uk/ current/m53/ (accessed 17 July 2015). 
51. The Society for All British and Irish Road Enthusiasts. Available online: www.sabreroads.org.uk/ (accessed on 17 July 2015).

52. Wiki Wirral.co.uk. "The M53 (+M531) - The History Of Wirrals Motorway." Available online: www.wikiwirral.co.uk/forums/ubbthreads.php/topics/101185/The_M53_M531_The_History_Of_ Wi.html (accessed on 17 July 2015).

53. Les Roberts, and Hazel Andrews. "(Un)Doing Tourism Anthropology: Outline of a Field of Practice." Journal of Tourism Challenges and Trends 6 (2014): 13-38.

54. Tim Ingold. The Perception of the Environment: Essays in Livelihood: Dwelling and Skill. London: Routledge, 2000.

55. Les Roberts. "Mapping Cultures-A Spatial Anthropology." In Mapping Cultures: Place, Practice, Performance. Edited by Les Roberts. Basingstoke: Palgrave, 2015, pp. 1-25.

56. Simon Gottschalk, and Marko Salvaggio. "Stuck Inside of Mobile: Ethnography in Non-Places." Journal of Contemporary Ethnography 44 (2015): 3-33.

57. Victor Turner. The Ritual Process: Structure and Anti-Structure. New York: Cornell University Press, 1969.

58. Michael Jackson. Minima Ethnographica: Intersubjectivity and the Anthropological Project. Chicago: University of Chicago Press, 1998.

59. Michael Jackson. Paths toward Clearing: Radical Empiricism and Ethnographic Inquiry. Bloomington: Indiana University Press, 1989.

60. Michael Jackson. "Introduction. Phenomenology, Radical Empiricism, and Anthropological Critique." In Things as They Are: New Directions in Phenomenological Anthropology. Edited by Michal Jackson. Bloomington: Indiana University Press, 1996, pp. 1-50.

61. Michael Jackson. Existential Anthropology: Events, Exigencies and Effects. Oxford: Berghahn, 2005.

62. Dimitra Gefou-Madianou. "Ethnography in Motion: Shifting Fields on Airport Grounds." In Ethnographic Practice in the Present. Edited by Marit Melhuus, Jon P. Mitchell and Helena Wulff. Oxford: Berghahn, 2009, pp. 152-68.

63. Les Roberts. "The Bulger Case: A Spatial Story.” The Cartographic Journal 51 (2014): 141-51.

(C) 2015 by the author; licensee MDPI, Basel, Switzerland. This article is an open access article distributed under the terms and conditions of the Creative Commons Attribution license (http://creativecommons.org/licenses/by/4.0/). 